\title{
ECONOMÍA CIRCULAR Y PROTECCIÓN DE LA SALUD
}

\section{CIRCULAR ECONOMY AND HEALTH PROTECTION}

\author{
AlejandRa Boto ÁlVAREZ \\ Profesora Titular de Derecho Administrativo \\ Universidad de Oviedo \\ botoalejandra@uniovi.es
}

Fecha de recepción: 15 de septiembre de 2021

Fecha de aceptación: 10 de noviembre de 2021

RESUMEN: Este trabajo indaga, dentro del llamado régimen jurídico de la economía circular, en los instrumentos que conectan con la protección de la salud. Tras poner en contexto ambas realidades (I), se exploran sus concomitancias, que plantean importantes retos conceptuales y metodológicos (II). Después, se acomete una revisión del ordenamiento rector en materia de economía circular en España, con el fin de considerar su impacto sobre la salud, en términos de oportunidades y riesgos transversales (III). Finalmente se atiende al sector sanitario, en tanto que escenario concreto donde aplicar esa economía circular, con atención a la situación generada por la pandemia (IV).

RESUM: Aquest treball indaga, dins l'anomenat règim jurídic de l'economia circular, en els instruments que connecten amb la protecció de la salut. Després de posar en context les dues realitats (I), s'exploren les seves concomitàncies, que plantegen importants reptes conceptuals i metodològics (II). També s'emprèn una revisió de l'ordenament rector en matèria d'economia circular a Espanya, amb la finalitat de considerar el seu impacte sobre la salut, en termes d'oportunitats i riscos transversals (III). Finalment, s'atén el sector sanitari, com 
a escenari concret on aplicar aquesta economia circular, amb atenció a la situació generada per la pandèmia (IV).

ABSTRACT: This paper focuses, within the so-called legal regime of the circular economy, at the instruments connecting with health protection. After contextualizing both realities (I), the research explores their concomitances, which pose relevant conceptual and methodological challenges (II). Afterwards, a review of the circular economy in Spain regulation is undertaken, in order to consider its impact on health, in terms of transversal opportunities and risks (III). Finally, the health sector as a concrete actor of the circular economy is considered, paying attention to the situation generated by the pandemic (IV).

PALABRAS CLAVE: Economía circular - Salud ambiental - Desarrollo sostenible - Gestión de residuos - Huella climática de la sanidad

PARAULES CLAU: Economia circular — Salut ambiental - Desenvolupament sostenible - Gestió de residus - Empremta climàtica de la assistència sanitària KEY WORDS: Circular economy - Environment health - Sustainable development - Waste management — Healthcare climate footprint

SUMARIO: I. INTRODUCCIÓN. II. ECONOMÍA CIRCULAR Y SALUD: CONCOMITANCIAS A EXPLORAR. 1. Cuestiones teóricas. 2. Cuestiones metodológicas. III. LA PROTECCIÓN DE LA SALUD EN LOS INSTRUMENTOS RECTORES DE LA ECONOMÍA CIRCULAR. 1. Aproximación preliminar: el contexto europeo. 2. La Estrategia Española de Economía Circular y el Plan de Acción 2021-2023. 3. Las leyes autonómicas sobre economía circular. IV. ECONOMÍA CIRCULAR Y SANIDAD: POSIBILIDADES Y BARRERAS. V. CONCLUSIONES. VI. BIBLIOGRAFÍA

\section{INTRODUCCIÓN 1}

\footnotetext{
1 El presente trabajo ha sido elaborado en el marco del proyecto de investigación de referencia MCIU-19-RTI2018-097840-B-I00, financiado por la Agencia Estatal de Investigación.
} 
En pleno proceso de construcción como concepto jurídico², la economía circular se ha convertido en un exitoso eslogan ${ }^{3}$ que, desde su inicial uso polisémico doctrinal ${ }^{4}$ salta sin tapujos, pero también sin mayor depuración, a instrumentos políticos declarativos y orientativos $\mathrm{y}$, desde un impulso programático a nivel europeo, poco a poco también a textos normativos domésticos. Tiende a aceptarse acríticamente porque participa de la fuerza de las cláusulas generales simples y gráficas, y de una connotación casi mística que comparte con ideas como la del desarrollo sostenible ${ }^{5}$. Así, ha comenzado a ubicarse entre nosotros con carácter principial y expansivo, como una pretendida herramienta novedosa para la tan ansiada consecución de la transición climática que protagoniza en la actualidad la lucha ambientalista y que también es un reto, en conexión con los mandatos constitucionales de preservación de los recursos naturales y funcionamiento eficiente de los poderes públicos, del derecho público en general ${ }^{6}$.

La finalidad del presente trabajo es el estudio de la forma y el alcance que la regulación de la economía circular puede tener como instrumento para la protección de salud, explorando sus concomitancias, más que plausibles, desde un concepto amplio, del que necesariamente hay que partir, de salud. Con esta perspectiva, se acometerá una revisión de los instrumentos jurídicos aprobados con carácter rector en materia de economía circular en España. Se considerará tanto su impacto sobre la salud, en términos de oportunidades y riesgos transversales, como el sector sanitario en tanto que escenario concreto, y ciertamente peculiar, donde aplicar esa economía circular.

\footnotetext{
${ }^{2}$ René Javier Santamaría Arinas, "Economía circular: líneas maestras de un concepto jurídico en construcción", en Revista catalana de dret ambiental, vol. 10, núm. 1, 2019.

${ }^{3}$ Ernest García, Ecología e igualdad. Hacia una relectura de la teoría sociológica en un planeta que se ha quedado pequeño, Tirant lo Blanch. Valencia, 2021, p. 222.

${ }^{4}$ Sobre el pluralismo conceptual y sectorial, y la diversidad de enfoque y contenidos de la noción de economía circular ofrece referencias esenciales Santamaría Arinas, "Economía circular..." cit., nota 2.

5 José Francisco Alenza García, "La economía circular en el derecho ambiental", en Actualidad jurídica ambiental, núm. 102, 2020, p. 225-249, en particular 239 y ss. La relación entre economía circular y sostenibilidad también se explora por Yolanda García Calvente, "Economía circular y ciudad", en María Rosario Alonso Ibáñez (dir.), La sostenibilidad socioeconómica de las ciudades. Estudios jurídicos, Tirant lo Blanch. Valencia, 2018, p. 317.
}

${ }^{6}$ Santamaría Arinas, "Economía circular..." cit., p. 17. 
Además del análisis directo de las fuentes jurídicas, el trabajo parte de una esencial revisión doctrinal. Según se viene indicando, no puede sorprender que exista un inflacionista interés académico por los temas de la economía circular.

Entre los juristas, tampoco es casualidad que hayan sido los ambientalistas, principalmente los expertos en residuos, quienes con mayor precisión se hayan acercado a la disección de este paradigma7. Ello tiene mucho que ver con el ámbito en que se han ido plasmando hasta ahora los desarrollos normativos que impulsa la economía circular8.

Otras disciplinas iuspublicistas que han centrado su atención en este tema lo han hecho, también por razones evidentes y siguiendo de cerca iniciativas institucionales, desde posiciones fiscalistas ${ }^{9}$, urbanas $^{10}$ y turísticas ${ }^{11}$.

Por su carácter transversal y estratégico, la economía circular ocupa también habitualmente a los expertos en contratación del sector público ${ }^{12}$, pero asimismo

\footnotetext{
${ }^{7}$ Además de las obras ya citadas de Santamaría Arinas y de Alenza García, que han visitado la cuestión de la economía circular en varias ocasiones, el "tridente" de los trabajos de ineludible cita se completa con los de Alba Nogueira López, entre los que destaca "Cuadrar el círculo. El complejo equilibrio entre el impulso de la economía circular y unas reglas de mercado expansivas", en InDret. Revista para el análisis del derecho, núm. 3, 2019.
}

${ }^{8}$ Alenza García, "La economía circular..." cit., p. 228.

9 Por todos: Antonio Vaquera García, De la tributación ambiental a las medidas financieras incentivadoras de la economía circular, Thomson-Reuters Aranzadi. Cizur Menor, 2020.

${ }^{10}$ Así, y en concreto desde una perspectiva de innovación social, puede verse García Calvente, "Economía circular y ciudad...", cit., p. 315 y ss. Entre los principales impactos sanitarios de las políticas urbanas pueden reseñarse la prestación de servicios públicos, los residuos, transportes y el desarrollo inmobiliario, en el marco de las llamadas smart cities: María García Caracuel, "EI papel de las smart cities en la transición hacia una economía circular y sus vías de financiación", en María Bertrán Girón y Julio Jiménez Escobar (dir.), El sistema jurídico ante la digitalización: estudios de derecho tributario, Tirant lo Blanch. Valencia, 2021, p. 235 y ss.

11 Iñaki Gaztelumendi, Anna Tarí y David Mora, Informe sobre Economía Circular aplicada al Turismo, SEGITTUR. Madrid, 2019. Disponible en <https://www.segittur.es/wpcontent/uploads/2019/09/Informe-sobre-economi\%CC\%81a-circular-aplicada-al-turismo-ok.pdf> [última consulta, 17 de agosto de 2021].

${ }^{12}$ Es lógico, si se tiene en cuenta la importancia creciente de la contratación social y ambiental, y el hecho de que la propia Comisión Europea haya editado una guía de orientación y buenas prácticas sobre "Contratación pública para una economía circular" < https://ec.europa.eu/environment/gpp/pdf/cp european commission brochure es.pdf> [última consulta, 17 de agosto de 2021]. Al respecto pueden verse los trabajos de Elisa Pérez de los Cobos Hernández, "La contratación pública ecológica como instrumento de impulso de la economía circular", en Actualidad Jurídica Ambiental, núm. 102, 2020, p. 677-691 y Juan José Pernás García, "Compra pública circular: análisis de las barreras, posibilidades y límites del marco jurídico y organizativo actual y propuestas de mejora", en Alba Nogueira y Xavier Vence (dir.), Redondear la economía circular. Del discurso oficial a las políticas necesarias, ThomsonReuters Aranzadi. Cizur Menor, 2021, p. 297 y ss. Estando este trabajo a punto de cerrarse vio la luz también el Dictamen de 9 de junio de 2021 (C 341/02) del Comité Económico y Social Europeo, Hacia una contratación pública circular <https://eur-lex.europa.eu/legal- 
ha suscitado enfoques doctrinales administrativistas más sectoriales. En particular aquí merecen ser destacados los que se acometen desde perspectivas con una incidencia sanitaria evidente, como la alimentaria ${ }^{13} \mathrm{o}$ la de movilidad ${ }^{14}$.

Puede apreciarse, sobre todo si se amplía el foco al derecho comparado ${ }^{15}$, que no se trata de un acervo doctrinal menor. Sin embargo, y más allá de alguna crónica sobre experiencias de aplicación efectiva de la economía circular en un contexto asistencial, hospitalario o ambulatorio, no parece que los juristas de la salud se hayan ocupado de estas cuestiones con una atención reseñable a nivel global ${ }^{16}$. Quizás esto tampoco deba extrañarnos, dado el omnipresente protagonismo absorbente de la pandemia, aunque tampoco ella huye de una posible lectura en clave circular ${ }^{17}$.

content/ES/TXT/?qid=1498995130169\&uri=CELEX\%3A52021IE0087> [última consulta, 30 de agosto de 2021].

${ }^{13}$ Subrayando la importancia prioritaria del sector alimentario para la economía circular puede verse Laura Salamero Teixidó, "El desperdicio de alimentos", en Laura Salamero Teixidó (dir.), Manual básico de derecho alimentario, Tirant lo Blanch. Valencia, 2019, p. 109 y ss., y de la misma autora, enfatizando el aspecto ambiental y la conexión con los residuos: "Nuevo reto medioambiental en la Unión Europea: la prevención y gestión de los residuos alimentarios según la Directiva Marco de Residuos tras su última modificación", en Revista española de derecho administrativo, núm. 203, 2020, p. 249 y ss.

${ }^{14}$ Entre los principales impactos de la movilidad sobre la salud cabe citar la contaminación, la actividad física, la ocupación del espacio o los propios accidentes de tráfico. Sobre la materia puede verse el trabajo de Carolyn Daher y Oriol Maquet, "La movilidad sostenible como una oportunidad estratégica para la salud pública y el bienestar en los contextos urbanos", en Antonio Fortes Martín (dir.), Movilidad urbana sostenible y acción administrativa. Perspectiva social, estrategias jurídicas y políticas públicas de movilidad en el medio urbano, Thomson-Reuters Aranzadi. Cizur Menor, 2019, p. 419 y ss. El director de esta última obra, en su trabajo más reciente ubica la calidad de vida de las personas como fundamento constitucional de una movilidad sostenible que va más allá del transporte (Los desplazamientos sostenibles en el derecho a la ciudad, lustel. Madrid, 2021, p. 41 y ss).

${ }^{15}$ Aunque este trabajo se centra en el contexto español, en su desarrollo se manejarán también algunas obras extranjeras de carácter internacional. El interés de derecho comparado en esta materia se evidencia, por todos, en María Teresa Armengol Rosinès, Laura Salamero Teixidó y Manel Plana Farran, "El desperdicio de alimentos como externalidad negativa: soluciones contenidas en la normativa francesa y propuestas para el caso español", en Revista catalana de dret ambiental, vol. 11, núm 1, 2020.

${ }^{16}$ La cuestión sí ha merecido la atención de la ingeniería hospitalaria. Sobre los aspectos económicos de la administración sanitaria siguen siendo referencia inexcusable las reflexiones de Santiago Rubio Cebrián, "Economía sanitaria", en Fernando Lamata (ed.), Manual de administración y gestión sanitaria, Díaz de Santos. Madrid, 1998, p. 635 y ss.

17 Aitana de la Varga Pastor, "La repercusión de la COVID-19 en la economía circular, en especial en la gestión de los residuos", en Jordi Jaria Manzano, Joseph Ramón Fuentes i Gaso, Paola Villavicencio Calzadilla y Víctor Merino Sancho (coord.), El impacto social de la COVID-19. Una visión desde el derecho, Tirant lo Blanch. Valencia, 2020, p. 306 y ss. 
Que el estudio de las implicaciones sanitarias de la transición a la economía circular ha sido muy limitado es algo que corroboran distintos estudios elaborados para la Organización Mundial de la Salud (OMS) desde la Oficina regional para Europa, que se analizarán en profundidad a continuación, tanto en la dimensión conceptual como metodológica.

\section{ECONOMÍA CIRCULAR Y SALUD: CONCOMITANCIAS A EXPLORAR}

\section{Cuestiones teóricas}

La Estrategia Española de Economía Circular (España Circular 2030) define la economía circular indicando en su glosario de términos que:

Es aquella en la que el valor de los productos, los materiales y los recursos se mantienen en la economía durante el mayor tiempo posible, y en la que se reduce al mínimo la generación de residuos, lo que constituye una contribución esencial a los esfuerzos de la UE encaminados a lograr una economía sostenible, descarbonizada, eficiente en el uso de los recursos y competitiva ${ }^{18}$.

La descripción es casi idéntica a la que manejó en su momento la Comisión Europea, en su Comunicación al Parlamento Europeo, al Consejo, al Comité Económico y Social Europeo y al Comité de las Regiones de 2 de diciembre de 2015, titulada Cerrar el círculo: un plan de acción de la UE para la economía circular'9.

A falta de una definición normativa estatal20, existen en este momento cuatro leyes autonómicas que han tratado de dar contenido jurídico al sintagma. Se

\footnotetext{
${ }^{18}$ En la p. 62: <https://www.miteco.gob.es/es/calidad-y-evaluacion-ambiental/temas/economiacircular/estrategia/> [última consulta, 17 de agosto de 2021].

19 COM (2015) 614 final. Disponible en <https://eur-lex.europa.eu/legalcontent/ES/TXT/?uri=CELEX\%3A52015DC0614> [última consulta, 17 de agosto de 2021].

${ }^{20}$ En el momento de escribir estas páginas está en tramitación el Proyecto de Ley de residuos y suelos contaminados, donde la economía circular es una expresión recurrente pero no aparece definida. En la exposición de motivos se indica, por ejemplo, que el texto tiene por objeto, entre otros, sentar los principios de la economía circular a través de la legislación básica en materia de residuos. El Proyecto también regula medidas fiscales para incentivar esa economía circular (el documento está disponible en el BOCG, Congreso de los Diputados, de 28 de mayo de 2021). En la doctrina, ha abogado por la necesidad de una definición uniforme del concepto de economía circular, demandando que sea incluso de nivel europeo, Alenza García, "La economía circular..." cit., p. 233.
} 
trata de tres leyes sobre cambio climático (Cataluña, 2017; Andalucía, 2018 e Islas Baleares, 2019) y de la Ley manchega que incorpora la locución en su propio título (Ley $7 / 2019$, de 29 de noviembre, de economía circular de Castilla-La Mancha). Con algunas diferencias léxicas y una semántica cada vez más compleja, los legisladores autonómicos han asumido en todos los casos un concepto amplio de economía circular, sin que siempre queden claras sin embargo sus fronteras y naturaleza jurídica²1. No es fácil dilucidar así si se trata de un objetivo o de un principio y, en este último caso, si resulta un principio sectorial de nuevo cuño o un principio rector general22. El enfoque es excesivamente difuso, y por ende impreciso, y lo más frecuente es que la expresión se use con fruición, pero también con tremenda superficialidad dogmática. Sucede en los preámbulos, donde las referencias a la economía circular resultan poco controvertidas, pues suele explicarse su contexto y además es tradicional el carácter estético de las exposiciones de motivos de las normas; pero, y esto es lo más llamativo, también sucede en la parte dispositiva ${ }^{23}$, como si su significado fuera evidente e incontrovertido.

Y nada más lejos de la realidad, pues la expresión resulta equívoca en su doble componente. En primer lugar, la dimensión económica, si bien es evidente24, no alcanza a agotar todo su sentido ni a explicar su relevancia. Es más, no resulta fácil acompasar la lógica en que se apoya la circularidad del sistema que se pretende conseguir con vigentes reglas económicas imperantes como la libre

\footnotetext{
${ }^{21}$ Al respecto puede verse el certero análisis de René Javier Santamaría Arinas, "Innovación normativa para la economía circular en leyes autonómicas", en Revista general de derecho administrativo, núm. 55, 2020, en particular en p. 10 y 11.

22 Sobre este tema, defendiendo que se trata fundamentalmente de un emergente paradigma metajurídico, que no es tan novedoso como se pretende, y reivindicado el valor de los principios clásicos: José Francisco Alenza García, "Principios clásicos para la nueva era del derecho ambiental", en Blanca Soro Mateo y Jesús Jordano Fraga (dir.), Viejos y nuevos principios del derecho ambiental, Tirant lo Blanch. Valencia, 2021, p. 11 y ss.

${ }^{23}$ Así por ejemplo, y sólo por citar un par de normas estatales de distintos ámbitos materiales, el artículo 6 de la Ley 7/2021, de 20 de mayo, de cambio climático y transición energética dispone, entre las acciones de digitalización para la descarbonización de la economía, la necesidad de abordar estratégicamente los retos y oportunidades que genera la incorporación de la tecnología digital a distintos sectores, entre los que se menciona la economía circular; y el artículo 49 del Código de Comercio regula desde 2018, entre la información que debe contener el estado de información no financiera consolidado, en el grupo de cuestiones medioambientales, la inclusión de datos sobre la economía circular y la prevención y gestión de residuos.
}

${ }^{24}$ Se ha dicho en este sentido que la economía circular no es otra cosa que una economía de mercado más eficiente: Alenza García, "La economía circular..." cit., p. 240. 
competencia o la unidad de mercado25. La "economía" es además un término polisémico, que no por casualidad comparte raíz etimológica con la "ecología" 26 y que, trufado por las ideas de la sostenibilidad ${ }^{27}$, admite adjetivaciones hasta la extenuación ${ }^{28}$.

El dibujo del círculo, cuyo triunfo se explica por contraposición a la lógica lineal de usar-y-tirar, puede ser también tildado de engañoso pues resulta incompatible con la misma naturaleza entrópica del propio proceso económico29. Ciertamente, la energía utilizada en cualquier desarrollo productivo se disipa de manera irrevocable y, en la práctica, ningún material es indefinidamente reciclable ${ }^{30}$. No hay un circulus perfecto; de hecho, si lo hubiera podría generarse incluso un efecto perverso, haciendo menos urgente la reducción de consumo de unos recursos naturales que dejarían de ser escasos si pudieran reutilizarse constantemente ${ }^{31}$. La ambivalencia resulta notoria.

Por su parte, la salud también debe entenderse en sentido amplio, no ya como ausencia de enfermedad sino, en consonancia con la definición institucional de la OMS, como el estado de completo bienestar físico, mental y social ${ }^{32}$. No es de extrañar, pues, que quepa apreciar una conexión palmaria entre la economía

25 Sobre la difícil compatibilidad del cambio sistémico ambiental que persigue la economía circular y el modelo económico actual: Nogueira López, cit.

${ }^{26}$ Con mayor profundidad puede verse Santamaría Arinas, "Economía circular..." cit., p. 9.

${ }^{27}$ Cabe recordar aquí precisamente la Ley $2 / 2011$, de 4 de marzo, de economía sostenible que a sus efectos la define como un patrón de crecimiento que concilie el desarrollo económico, social y ambiental en una economía productiva y competitiva, que favorezca el empleo de calidad, la igualdad de oportunidades y la cohesión social, y que garantice el respeto ambiental y el uso racional de los recursos naturales, de forma que permita satisfacer las necesidades de las generaciones presentes sin comprometer las posibilidades de las generaciones futuras para atender sus propias necesidades.

${ }^{28}$ Desde colores identificativos (verde, azul, naranja) a descriptores más evocadores (racional, colaborativa, inteligente, ecológica, integradora). Sobre el tema: Alenza García, "La economía circular..." cit., p. 244.

${ }^{29}$ García, Ecología e igualdad... cit., p. 222-223.

30 Por eso resulta especialmente acertada la visión, también gráfica, de un bucle o una espiral que impera en Elena Pérez Lagüela y Luis Miguel Jiménez Herrero (coord.), Economía circularespiral. Transición hacia un metabolismo económico cerrado, ASYPS- Ecobook. Madrid, 2019.

${ }^{31}$ García, Ecología e igualdad... cit., p. 226.

32 Preámbulo de la Constitución de la Organización Mundial de la Salud, que fue adoptada por la Conferencia Sanitaria Internacional, celebrada en Nueva York del 19 de junio al 22 de julio de 1946, y firmada el 22 de julio de 1946 por los representantes de 61 Estados (Official Records of the World Health Organization, núm. 2, p. 100). Entró en vigor el 7 de abril de 1948 y la definición no ha sido modificada desde entonces. 
circular y las cuestiones sanitarias. Se trata, no obstante, de una relación que la mayor parte de las veces permanece implícita, y cuyo estudio no se ha acometido aún de una manera elaborada. Las definiciones normativas existentes hasta el momento en España desde luego no abordan ese vínculo de forma expresa, y en general la conceptualización doctrinal de la economía circular tampoco suele ocuparse de ello; a lo sumo se formulan remisiones genéricas, indicando, por ejemplo, la reducción de impactos que generaría el uso eficiente de los recursos, la orientación dietética o la mejora integral del ambiente ${ }^{33}$. Un aspecto crucial y aún por desarrollar es la intersección entre la normativa de reutilización/reciclaje de materiales y la de sustancias peligrosas ${ }^{34}$.

En un informe elaborado en 2016, la Agencia Europea de Medio Ambiente (EEA, por sus siglas en inglés) contextualizaba la transición hacia la economía circular en un marco más amplio, en conexión con lo que se denominaba "economía verde". Para la Agencia, economía circular, crecimiento verde y desarrollo sostenible son términos relacionados, pero no sinónimos. Según ese informe, una economía circular no aborda plenamente la conservación del capital natural y la prevención de los riesgos medioambientales para la salud y el bienestar humanos. De hecho, la economía circular se representaba gráficamente como el núcleo de una perspectiva de economía verde que amplía el enfoque desde el uso de desechos y materiales hasta la resiliencia de los ecosistemas, y la salud y el bienestar humanos. Se reproduce la figura por su gran impacto visual35:

\footnotetext{
${ }^{3}$ Vasileios Rizos, Katja Tuokko y Arno Behrens, "The Circular Economy. A review of definitions, processes and impacts", en CEPS Research Report, núm. 8, 2017, en particular p. 10, 15 y 21. El informe puede descargarse gratuitamente desde la web del Centre for European Policy Studies (CEPS) < www.ceps.eu> [último acceso, 19 de agosto de 2021].

${ }^{34}$ En la línea apuntada por Naoko Tojo y Äke Thidell, "Material recycling without hazardous substances. Interplay of two policy streams and impacts on industry", en Eléonore Maitre-Ekern, Carl Dalhammar y Hans Christian Bugge (ed.), Preventing environmental damage from products: an analysis of the policy and regulatory framework in Europe, Cambridge University Press. Cambridge, 2018, p. 253 y ss. Desde Argentina, y con ocasión de una reciente reforma legislativa inspirada en la economía circular, ha reflexionado sobre la relación conceptual entre "insumo" y "residuo peligroso" Carlos A. Luisoni, en "Prohibición de ingreso al territorio nacional de residuos peligrosos", en Revista de Derecho Ambiental, núm. 65, 2021, p. 149 y ss.

35 Informe 2/2016 de la EEA: Circular economy in Europe. Developing the knowledge base, Oficina de publicaciones de la UE. Luxemburgo, 2016, p. 31. Disponible en < https://www.eea.europa.eu/publications/circular-economy-in-europe> [última consulta, 19 de agosto de 2021].
} 


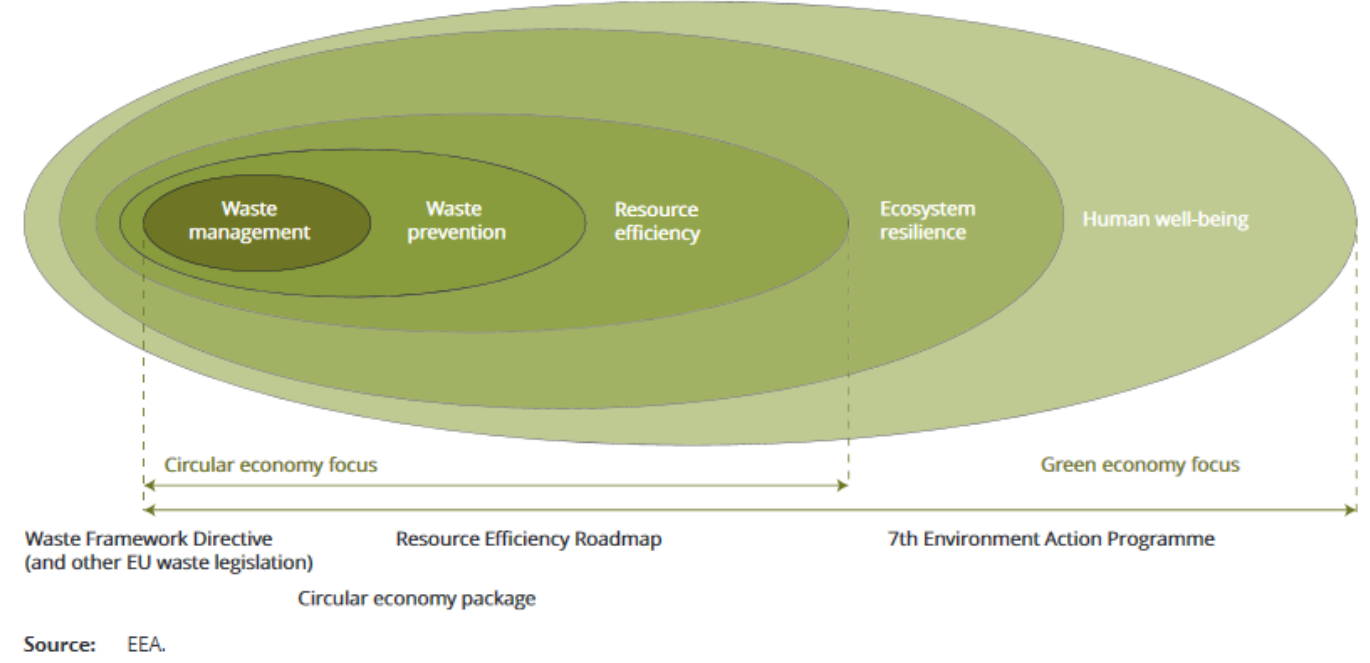

En general, el foco en el análisis de las implicaciones de la economía circular se ha puesto en los polos de la producción y el consumo, y los efectos se han analizado desde esa contextualización más amplia y transversal. Una perspectiva totalmente distinta, que busca enmarcar la economía circular en cuestiones de salud, es la que animó el informe elaborado en 2018 por la Oficina regional para Europa de la OMS ${ }^{36}$. Uno de sus mensajes más importantes es que la transición circular es susceptible de generar importantes beneficios para la salud, tanto directos (por ahorros en el funcionamiento de la atención sanitaria derivados de cambiar los patrones de utilización de bienes, por ejemplo) como indirectos (a partir de un menor impacto ambiental de los procesos generales de producción y consumo, o porque la reducción de costes de uso y consumo genera ahorros en los hogares que pueden dedicarse a la mejora de las coberturas de atención). Pero existen también riesgos no menores, derivados de la manipulación de productos químicos o plásticos en el reciclaje, de la exposición a desechos electrónicos o de la reutilización de las aguas.

Las ventajas son muchas veces de carácter global y plazo largo (mitigación del cambio climático, mejora de la calidad del aire), pero los riesgos tienden a estar más localizados en el espacio y en el tiempo, y a tener un impacto social marcado, ante la inclinación a desplazar ciertos residuos a zonas de rentas más bajas, porque la localización residencial en áreas insalubres tiene también un carácter distributivo y porque la salud laboral asimismo está influida por el nivel

${ }^{36}$ Alistair Hunt, Nick Dale y Frank George, Circular Economy and Health: opportunities and risks, OMS. Copenhagen, 2018. 
de cualificación ${ }^{37}$. La perspectiva aquí no puede ser sólo económica, sino también comunitaria, incluyendo las cuestiones de género ${ }^{38}$. El análisis social torna fundamental, como sucede también con otras políticas clave en materia de sostenibilidad, como la vivienda ${ }^{39}$.

Con la finalidad de identificar impactos sanitarios en el modelo de economía circular, la Oficina regional para Europa de la OMS, en este informe de 2018 empleó un marco conceptual basado en el modelo DPSEEA (Ilamado así por las siglas en inglés de sus principales componentes: fuerzas impulsoras, presión, estado, exposición, efecto, acción ${ }^{40}$ ), que fue desarrollado por la propia OMS en los años $90^{41}$. Se identificaron, aplicando ese marco conceptual a la literatura especializada sobre el tema, escasa como ya se ha contado, múltiples impactos potenciales en salud de distintos procesos de economía circular, positivos y negativos, directos e indirectos, pero la conclusión general es la necesidad de realizar estudios más profundos y desarrollar una metodología más depurada ${ }^{42}$. Entre esos impactos, sin ánimo exhaustivo, el informe cita varios casos de estudio, que van desde la reutilización de las aguas a la contaminación atmosférica ${ }^{43}$. Uno de ellos es el propio sector de la atención sanitaria, en particular los hospitales, como actores de la economía circular; volveremos sobre ello más adelante. Ahora, y teniendo en cuenta que estamos en una fase de exploración de concomitancias más generales, se seleccionan aquí para presentarse de forma sintética los dos casos de estudio que tienen, a mi juicio, un carácter más concreto y a la vez más interesante, por entremezclar, además

\footnotetext{
${ }^{37}$ Caradee Y. Wright, Linda Godfrey, Giovanna Armiento, Lorren K. Haywood, Roula Inglesi-Lotz, Katrina Lyne y Patricia Nayna Schwerdtle, "Circular economy and environmental health in lowand middle-income countries", en Globalization and Health, núm. 15, 2019.

38 Hunt, Dale y George, Circular Economy...cit., p. 14-19.

39 Dolors Canals i Ametller, "La efectividad de la regulación normativa del derecho a una vivienda digna y adecuada: una crítica desde el análisis social del derecho", en Natalia Paleo Mosquera (coord.), Políticas y derecho a la vivienda: gente sin casa y casas sin gente, Tirant lo Blanch. Valencia, 2020, p. 97-136.

${ }^{40}$ Hunt, Dale y George, Circular Economy...cit., p. 20 y ss.

${ }^{41}$ Carlos F. Corvalán, David J. Briggs, Gerhard Zielhuis (ed.), Decision-making in environmental health: from evidence to action, OMS-E\&FN Spon. Londres, 2000. Accesible de forma gratuita en <https://apps.who.int/iris/handle/10665/42304> [último acceso, 20 de agosto de 2021].

42 Hunt, Dale y George, Circular Economy ...cit., p. 56-57.

${ }^{43}$ El resto son los productos químicos, el desperdicio tecnológico y el cambio climático.
} 
de la tecnología, la economía y los recursos naturales, también pautas sociales y por ende implicaciones jurídicas evidentes ${ }^{44}$ : el sector alimentario y el edificatorio. Se trata además de ámbitos sectoriales que han sido de interés para la academia española, como ya se ha comentado.

Respecto a la alimentación, cabe identificar impactos cruzados directos de la circularidad en materia de seguridad y lucha contra el desperdicio. Por un lado, existen experiencias que permiten deducir importantes ahorros domésticos en la reducción del desperdicio alimentario, amén de una cierta justicia social si se donan los excedentes. Ello puede suponer impactos positivos en salud, por la mayor disponibilidad de renta para dedicarla a coberturas sanitarias, y la mejora del estado general de las personas socialmente más desfavorecidas. Por otro lado, el reciclaje del material de embalaje alimentario plantea retos de seguridad, habiéndose encontrado algunas evidencias de presencia de químicos preocupantes en los propios envases, o en el compostaje al que acaban llegando los materiales de envasado no plásticos. El riesgo sanitario que se genera con la entrada de estos contaminantes en la cadena alimentaria puede relacionarse, a falta de mayor investigación, con casos de cáncer y enfermedades endocrinas. También se apunta a que la implementación de la economía circular podría promover no sólo la producción, sino también el consumo de alimentos más saludables, a través del desarrollo de electrodomésticos inteligentes y la mayor disponibilidad de productos frescos y sanos, por ejemplo. De ello derivaría una reducción de las tasas de obesidad y sobrepeso, que es claramente un objetivo de salud, y la consiguiente reducción económica de los costes por atención sanitaria. El propio informe subraya empero que se trata de impactos indirectos, difíciles de cuantificar y dependientes de un cambio cultural y social que requiere de mayor monitorización, y de una perspectiva en realidad más amplia que la de la economía circular ${ }^{45}$.

Respecto a la construcción, la literatura sobre economía circular es insistente en la identificación de los beneficios de todo nivel derivados de la profundización de

\footnotetext{
${ }^{44}$ En esta línea, el jurista se plantea desconcertado si el cambio de paradigma debe ser económico o social. Defendiendo los valores del derecho ambiental: Alenza García, "La economía circular..." cit., p. 243 y ss.

${ }^{45}$ Hunt, Dale y George, Circular Economy...cit., p. 42-43.
} 
sus principios y métodos en el diseño, la construcción, la planificación de la edificación y la lógica de las smart cities. De todo ello pueden extraerse también beneficios para la salud, por el uso de nuevos materiales no tóxicos en la construcción, la mejora de la calidad del aire por la optimización de las infraestructuras de comunicación y transporte, la reducción de emisiones y el progreso en el bienestar general ante la mejora de la calidad del medio urbano. Parecen sinergias incontestables, pero la naturaleza y extensión de los beneficios para la salud necesita de nuevo de más estudios. Al mismo tiempo, tampoco pueden obviarse ciertos riesgos pues, si bien parece evidente que la salud de los trabajadores mejora en oficinas con luz natural y buena ventilación, habrá otros que no se vean afectados, entre los que el estudio cita los implicados en la producción de paneles solares, por ejemplo46. Dado que la desigualdad es un factor esencial en el estado de salud, los estudios que profundicen en la identificación de impactos sanitarios de la economía circular necesariamente tendrán que tener en cuenta la dimensión social. En las cuestiones metodológicas nos detendremos a continuación.

\section{Cuestiones metodológicas}

En consonancia con la falta de atención general a las interacciones sanitarias de la economía circular que se viene señalando, la relevancia de la economía circular en la consecución de objetivos sanitarios ha sido también muy poco resaltada al establecer vínculos en el marco de la Agenda 2030 de Naciones Unidas. Es frecuente encontrar referido el alineamiento directo de la economía circular con el objetivo de desarrollo sostenible (ODS) número 12 de la Agenda (producción y consumo responsables), y en menor medida con otros objetivos, como los números 7 (energía asequible y no contaminante), 11 (ciudades y comunidades sostenibles) $\circ 13$ (acción por el clima) ${ }^{47}$. Las potencialidades

\footnotetext{
${ }^{46}$ Hunt, Dale y George, Circular Economy...cit., p. 47 y ss.

47 Existen documentos internos de la ONU que declaran la economía circular como "prometedora" para estos objetivos, y también para los números 14 (vida submarina) y 15 (vida de ecosistemas terrestres). En ocasiones se genera cierta confusión respecto al objetivo número 6 (agua limpia y saneamiento), pero el número 3 , que busca garantizar una vida sana y promover el bienestar de todos a todas las edades, no suele estar presente. Por todos puede verse: < https://www.un.org/en/ga/second/73/jm_conceptnote.pdf> [última consulta, 19 de agosto de 2021].
} 
respecto al objetivo número 3 (salud y bienestar) pasan en cambio más desapercibidas ${ }^{48}$, y estudios empíricos recientes han apuntado de hecho a que las metas fijadas para este objetivo son de las que tienen un vínculo más débil con las prácticas de la economía circular ${ }^{49}$.

En este punto quizás no huelgue recordar que la Agenda 2030 plantea 17 objetivos y 169 metas de carácter integrado e indivisible que conjugan las dimensiones económica, social y ambiental. Aunque cada meta está asociada a un objetivo, y dado que la realidad es esquiva a compartimentos estanco, es frecuente que aparezcan sinergias, complementariedades y compensaciones entre los objetivos ${ }^{50}$. La coherencia es una aspiración irrenunciable y por esto también los indicadores estadísticos que se han ido desarrollando para su medida son en muchas ocasiones polivalentes, es decir, se utilizan para evaluar más de un objetivo ${ }^{51}$.

Y ello tiene una especial importancia al hablar de la relación entre la economía circular y el objetivo número 3, pues los mismos estudios antes comentados, que han demostrado que la mayoría de las metas bajo este objetivo no tienen relación con las prácticas de economía circular, apuntan también al mismo tiempo a que la implementación de prácticas circulares bajo objetivos como los números 6 y 7 (referidos a agua y energía) contribuiría significativamente al avance en salud y bienestar ${ }^{52}$. No toda la relación genera empero sinergias positivas, pues también cabe apreciar un posible efecto negativo de esas prácticas, sobre todo en temas

48 También a la inversa, los estudios sobre el ODS 3 sólo tocan muy tangencialmente el fenómeno de la economía circular. A modo de síntesis pueden verse las reflexiones de Sameera Hussain, Dena Javadi, Jean Andrey, Abdul Ghaffar y Ronald Labonté, "Health intersectoralism in the Sustainable Development Goal era: from theory to practice", en Globalization and Health, núm. 16, 2020.

${ }^{49}$ Patrick Schroeder, Kartika Anggraeni y Uwe Weber, "The Relevance of Circular Economy Practices to the Sustainable Development Goals", en Journal of Industrial Ecology, vol. 23, núm. 1, 2019, p. 77 y ss., en particular p. 81.

50 Puede verse al respecto el informe elaborado por la Organización para la Cooperación y el Desarrollo Económicos (OECD, por sus siglas en inglés): Better Policies for Development 2015: Policy Coherence and Green Growth, OECD Publishing. Paris, 2015. Disponible en < https://www.oecd.org/development/Better\%20Policies\%20for\%20Development_2015.pdf> [última consulta, 19 de agosto de 2021].

51 Para mayor detalle puede consultarse la información institucional panorámica sobre los ODS del portal web de la Oficina Estadística de la Unión Europea (EUROSTAT), en inglés, francés o alemán: <https://ec.europa.eu/eurostat/web/sdi/overview> [última consulta, 19 de agosto de 2021].

52 Schroeder, Anggraeni y Weber, “The Relevance of..." cit., p. 87. 
de reutilización de aguas, sobre metas propias del objetivo número 3, como la 3.3 (poner fin a las epidemias del SIDA, la tuberculosis, la malaria y las enfermedades tropicales desatendidas y combatir la hepatitis, las enfermedades transmitidas por el agua y otras enfermedades transmisibles) y la 3.9 (reducir considerablemente el número de muertes y enfermedades causadas por productos químicos peligrosos y por la polución y contaminación del aire, el agua y el suelo) ${ }^{53}$. Esos efectos perniciosos se producen además, como ya se había apuntado, de manera socialmente muy desequilibrada, afectando más sensiblemente a las personas y los grupos vulnerables, mayoritariamente empleados en trabajos de reciclaje informal o que viven en condiciones higiénicas deficitarias ${ }^{54}$.

Para el objetivo de desarrollo sostenible número 3, la ONU ha definido 9 metas, numeradas correlativamente, y 4 medios de implantación, identificados por letras, de calado muy diverso ${ }^{55}$. Entre los que apriorística y potencialmente tienen mayor capacidad de verse influidos por la economía circular podrían destacarse, además de las metas 3.3 y la 3.9 ya comentadas, los medios 3.b (acceso a los medicamentos) y 3.d (reducción y gestión de los riesgos para la salud). Para confirmar estas interrelaciones serían necesarios sin embargo estudios empíricos más detenidos. Parece difícil que puedan darse, al menos desde una perspectiva puramente analítico-cuantitativa, porque no se han fijado indicadores concretos para este objetivo en los que se aprecie fácilmente influencia relativa de la economía circular ${ }^{56}$.

\footnotetext{
${ }^{53}$ Schroeder, Anggraeni y Weber, "The Relevance of..." cit., p. 86.

54 Precisamente por ello, también puede considerarse que los impactos sanitarios positivos de la economía circular les suponen ganancias proporcionalmente mayores: Hunt, Dale y George, Circular Economy...cit., p. 16-19.

${ }^{55}$ Más información en < https://www.un.org/sustainabledevelopment/health/> [última consulta, 19 de agosto de 2021].

${ }^{56}$ El establecimiento de la Agenda 2030 mediante la Resolución 70/1, de 25 de septiembre de 2015, de la Asamblea General de la ONU, responsabiliza a cada gobierno de su implementación, teniendo en cuenta las prioridades y particularidades de cada país. Sin embargo, el sistema de Naciones Unidas se comprometió a apoyarlos y estableció una lista de indicadores globales que deberán complementar los sistemas de medición regional y nacional. Estos son un total de 232, con diferente grado de claridad conceptual y aceptación metodológica. Para el objetivo número 3 se establecieron 27 indicadores, tal y como puede verse en el Marco de indicadores mundiales para los ODS y metas de la Agenda 2030, acordado por la Comisión de Estadística de las Naciones Unidas celebrada en marzo de 2017 (Anexo a la Resolución 71/313). En la UE, en la actualidad se ofrecen datos para 11 indicadores en este objetivo, que miden en concreto la esperanza de vida en buenas condiciones sanitarias; la proporción de población con buena salud
} 
En España, el Instituto Nacional de Estadística (INE) ofrece de manera actualizada información de distintos indicadores para valorar el progreso en las metas de cada objetivo. En el momento de cerrar este trabajo se ofrecen datos para 23 indicadores del objetivo de salud, y están aún explorándose las fuentes de datos para poder medir el resto ${ }^{57}$. Entre los pendientes están precisamente algunos en relación con las metas y medios que aquí se han destacado; en concreto en la meta 3.9, y los medios 3.b y 3.d.

Se trata del 3.9.1 (tasa de mortalidad atribuida a la contaminación de los hogares y del aire ambiente), 3.9.2 (tasa de mortalidad atribuida al agua insalubre, el saneamiento deficiente y la falta de higiene), 3.b.3 (proporción de centros de salud que disponen de un conjunto básico de medicamentos esenciales asequibles de manera sostenible) y 3.d.2 (porcentaje de infecciones del torrente sanguíneo debidas a determinados organismos resistentes a los antimicrobianos seleccionados), lo que da una idea de lo difícil que resulta arquear estas cuestiones.

Por eso es vital atender al diseño de las políticas y herramientas de economía circular, y buscar la integración de la perspectiva de la protección de la salud. En ese enfoque, además, no deberían obviarse actores fundamentales en la consecución tanto de los ODS como de la economía circular, como son las entidades locales ${ }^{58}$.

En un informe de 2019 que da continuación al comentado en el epígrafe precedente, la Oficina regional para Europa de la OMS profundizó sobre distintas

percibida; la prevalencia del tabaquismo; la tasa de mortalidad atribuida a tuberculosis, VIH y hepatitis; la tasa de mortalidad prevenible y tratable estandarizada; las necesidades insatisfechas autoinformadas de examen médico y atención sanitaria; la tasa de obesidad; las muertes en accidentes de trabajo; el porcentaje de población que vive en hogares ruidosos por razón de pobreza; las muertes en accidentes de tráfico y la exposición a la contaminación atmosférica por partículas. Sólo esta última parece tener una relación más o menos clara con la economía circular. Todos los datos pueden verse en < https://ec.europa.eu/eurostat/web/sdi/good-health-and-wellbeing $>$ [última consulta, 19 de agosto de 2021].

${ }^{57}<$ https://www.ine.es/dyngs/ODS/es/index.htm> [última consulta, 19 de agosto de 2021].

58 Sobre este tema, desde distintas perspectivas: René Javier Santamaría Arinas, “¿Hacia la economía circular europea sin los municipios?: una crítica sectorial de la Ley de racionalización y sostenibilidad de la administración local", en Revista vasca de administración pública, núm. 99100, 2014, p. 2671-2701 y Dolors Canals i Ametller, "La operatividad de la economía circular y su gestión local”, en José Esteve Pardo (dir.), La Agenda 2030: implicaciones y retos para las administraciones locales, Fundación Democracia y Gobierno Local. Madrid, 2021, p. 241-272. 
evaluaciones de impacto de estrategias, políticas, planes, programas y proyectos que podrían tener interés en el tema que nos ocupa ${ }^{59}$.

Respecto a la evaluación de marcos estratégicos de economía circular, se destaca el interés de incluir las externalidades sanitarias en el análisis macroeconómico de los impactos, y la necesidad de una focalización directa en el sector sanitario. No son fórmulas mágicas, de todas formas, porque la fijación de externalidades siempre será tentativa, y porque los impactos de la economía circular en la salud van más allá del ámbito estrictamente sanitario. Lo más adecuado parece ser la identificación y caracterización de esos impactos, implicando especialistas en salud y bienestar en el desarrollo estratégico, y admitiendo a evaluación impactos indirectos a los que normalmente no se suele atender en estos instrumentos ${ }^{60}$.

En relación con las políticas, planes, programas y proyectos, el informe valora como instrumento ideal la evaluación del impacto en salud, desarrollada por la propia OMS. Este instrumento en nuestro país está previsto por el artículo 35 de la Ley $33 / 2011$, de 4 de octubre, general de salud pública, para las "normas, planes, programas y proyectos que se seleccionen por tener un impacto significativo en la salud". Dado que, como se ha visto, conceptualmente no existe una creencia generalizada de que ese impacto sea significativo, no es de extrañar que este tipo de evaluación descanse sobre una aplicación voluntarista ${ }^{61}$.

Otros instrumentos que podrían resultar útiles para la evaluación de la incidencia sanitaria de la economía circular son los de carácter ambiental (evaluación

\footnotetext{
59 Nick Dale, Alistair Hunt, Thomas B. Fischer, Fintan Hurley, Julia Nowacki y Frank George, Assessing the health impacts of a circular economy, OMS. Copenhagen, 2019.

${ }^{60}$ Dale, Hunt, Fischer, Hurley, Nowacki y George, Assessing the health... cit., p. 14.

${ }^{61}$ Entre los instrumentos que se han sometido a esa evaluación está por ejemplo el "Plan Integral de Residuos de Andalucía. Hacia una economía circular 2030", si bien en el informe resultante se indica que no se aspira a realizar la evaluación de impacto en salud tal y como es entendida por la comunidad científica a nivel internacional, sino que se trata "de una valoración preliminar del posible impacto que sobre la salud puede tener este Plan sin poder considerarse exhaustivo, ya que las repercusiones sobre la salud de la ciudadanía son tan vastas, variadas y frecuentemente difíciles de valorar y/o cuantificar que el estudio se ha limitado a los aspectos más significativos, inmediatos y directos, y siempre dentro del estado del conocimiento actual". El informe puede localizarse en https://www.juntadeandalucia.es/export/drupaljda/normativa_en_elaboracion/20/06/Informe\%20 Evaluaci\%C3\%B3n\%20Impacto\%20en\%20Salud.pdf> [última consulta, 20 de agosto de 2021].
} 
ambiental estratégica y evaluación de impacto ambiental), pues la salud humana es uno de los aspectos a considerar en ellos. Así lo hace por ejemplo en nuestro caso la Ley 21/2013, de 9 de diciembre, de evaluación ambiental. Sin embargo, lo que en la práctica cubren estas evaluaciones suelen ser consideraciones principalmente biofísicas, en menor medida sociales ${ }^{62}$, y nunca conductuales ${ }^{63}$. Además, desde la perspectiva del análisis ambiental de un concreto instrumento será complicado aislar impactos propiamente de salud, y en consecuencia su monitorización será también más compleja; esa es también la debilidad de otros métodos, como el análisis del ciclo de vida ${ }^{64}$. A mayores, las evaluaciones de este tipo se centran en la identificación de impactos generalmente negativos, y difícilmente podrán tener el rol de acompañamiento y fomento que se busca con la evaluación del impacto en salud65.

El informe se esfuerza después en desarrollar una lista de cuestiones clave que permitirían detectar los casos en que procedería realizar, bien una evaluación de impacto en salud, bien otra evaluación sectorial que incluyera la salud. Estas parten de plantear, en primer término, de cara a la identificación de posibles impactos, si existen impactos directos (positivos o negativos) en salud pública, laboral, mental y bienestar; si existen impactos indirectos vía cambios sociales, económicos o ambientales, y si existen impactos específicos para el sector de la asistencia sanitaria, en la forma de ahorros de funcionamiento, aumento de potenciales demandantes con acceso al servicio, pero reducción de la demanda efectiva, etc. Para cada impacto posible así identificado habría que plantearse, respecto a los efectos, si serán diferenciales en función de los grupos socioeconómicos de la población; su reversibilidad y extensión en el tiempo; la

\footnotetext{
62 La norma española prevé, por ejemplo, que la selección de la mejor alternativa deberá estar soportada por un análisis global multicriterio, que tenga en cuenta, no sólo aspectos económicos, sino también los de carácter social y ambiental. Desde la sociología se ha reclamado, sin embargo, un mayor rigor en la evaluación de los aspectos sociales. Por todos Mercedes Pardo Buendía, La evaluación del impacto ambiental y social para el siglo XXI: teorías, procesos, metodología, Fundamentos. Madrid, 2002.

63 Dale, Hunt, Fischer, Hurley, Nowacki y George, Assessing the health ... cit., p. 18-20.

${ }^{64}$ Se trata de una técnica que entre nosotros ha convertido en familiar la normativa de contratación del sector público, precisamente procedente del ámbito de la economía circular, y que es susceptible de identificar también impactos de salud de productos concretos. Sobre este tema, desde distintas perspectivas, pueden verse los trabajos contenidos en Ximena Lazo Vitoria (dir.), Compra pública verde, Atelier. Madrid, 2018.

${ }^{65}$ Dale, Hunt, Fischer, Hurley, Nowacki y George, Assessing the health... cit., p. 22.
} 
capacidad para generar alarma social y/o apoyo público, y las posibles sinergias que puedan convertir otros factores aisladamente insignificantes en elementos combinados de interés. $\mathrm{Y}$, finalmente, respecto a la propia evaluación, convendría dilucidar si llevarla a cabo genera valor añadido al proceso de elaboración, evitar duplicidades y ponderar los gastos de recursos de todo tipo que consumiría ${ }^{6}$.

Como su predecesor, este informe acaba concluyendo con el estudio de algunos casos sectoriales, que en este caso los autores escogen de manera mucho más selectiva. Son, de nuevo y no por casualidad, el sector asistencial, la construcción y la alimentación. Dejando el primero para un estudio más específico al final de este trabajo, se exponen a continuación, también de manera sintética los principales hallazgos de la Oficina regional de la OMS para Europa, que apuntan a la necesidad de evaluar con mayor detalle distintas oportunidades y riesgos sanitarios vinculados a acciones concretas de economía circular.

En relación con la alimentación, se subraya en primer lugar la importancia de desarrollar adecuados estándares de seguridad y salud alimentaria. Se sugiere además, como campo para la evaluación global, la necesidad de profundizar en el impacto de las acciones de economía circular vinculadas a la lucha contra el desperdicio alimentario en la salud pública y laboral; para la evaluación de políticas, las vinculadas a las de fomento de una alimentación equilibrada y saludable; para una evaluación de impacto en salud, las acciones vinculadas a la reutilización de la biomasa, y se recomienda que se generalicen las evaluaciones sectoriales con consideración de factores de salud de acciones como las innovaciones en materia de bancos de alimentos ${ }^{67}$.

Y respecto a la construcción, se resalta la procedencia de evaluaciones amplias respecto a los planes estratégicos más ambiciosos; de evaluaciones de impacto en salud de todos los programas y grandes proyectos de economía circular urbana, y de evaluaciones sectoriales con consideración de factores de salud respecto a otras iniciativas más modestas. El análisis del ciclo de vida, con

\footnotetext{
${ }^{66}$ Dale, Hunt, Fischer, Hurley, Nowacki y George, Assessing the health ... cit., p. 53-54.

${ }^{67}$ Dale, Hunt, Fischer, Hurley, Nowacki y George, Assessing the health... cit., p. 31-33.
} 
atención a los impactos en salud, es de gran interés en obras de construcción y regeneración urbana, incluso más allá del sector público68.

Será necesario trabajar la cultura del cambio, para identificar no sólo impactos evidentes sino también indirectos, y tanto positivos como negativos. La individualización de indicadores y de métricas específicas es inaplazable, y el marco de seguimiento para la economía circular aprobado por la UE en 2018 no resulta, tampoco en este punto, prometedor. Ese instrumento realiza un seguimiento a través de diez indicadores que reflejan los avances de cada uno de los países miembros en la transición hacia una economía circular ${ }^{69}$. Por motivos organizativos los indicadores medidos se clasifican en cuatro grandes áreas temáticas que evidencian, a pesar de las declaraciones iniciales, una perspectiva reducida de la circularidad 70 . Son producción y consumo ${ }^{71}$, gestión de residuos ${ }^{72}$, materiales reciclados ${ }^{73}$ y competitividad e innovación ${ }^{74}$. Puede verse que el foco se coloca sobre los materiales y deja de lado las cuestiones sociales.

A continuación se trata de analizar el estado de la cuestión en los últimos instrumentos rectores de la economía circular aprobados en España, con una previa consideración del contexto general en el que se integran. El objetivo es identificar si existen, en el incipiente régimen jurídico de la economía circular, instrumentos que contemplen la protección de la salud y analizarlos en su caso.

${ }^{68}$ Dale, Hunt, Fischer, Hurley, Nowacki y George, Assessing the health ... cit., p. 29-31.

69 COM (2018) 29 final. $\quad<$ https://eurlex.europa.eu/LexUriServ/LexUriServ.do?uri=COM:2018:0029:FIN:ES:PDF> [última consulta, 4 de noviembre de 2021].

${ }^{70}$ Criticando en general la extensión y elección de los indicadores de ese Marco puede verse el trabajo de Leandro Llorente y Xavier Vence, "Decoupling or 'Decaffing'? The Underlying Conceptualization of Circular Economy in the European Union Monitoring Framework", en Sustainability, 2019, 11(18), 4898.

${ }^{71}$ Los indicadores medidos son autosuficiencia de materias primas para la producción en la UE, contratación pública ecológica, generación de residuos y desperdicios de comida.

72 Esta categoría comprende indicadores de tasas de reciclaje y flujos de residuos específicos (embalajes, biorresiduos, residuos electrónicos, etc.).

${ }^{73}$ Esta categoría contiene dos indicadores: Contribución de los materiales reciclados a la demanda de materias primas, y comercio de materiales reciclados entre Estados miembros de la UE y con el resto del mundo.

${ }^{74}$ En esta área se comprenden dos indicadores: inversión privada, empleo y valor añadido bruto, y patentes relacionadas con el reciclaje y los materiales reciclados. 


\section{LA PROTECCIÓN DE LA SALUD EN LOS INSTRUMENTOS RECTORES DE LA ECONOMÍA CIRCULAR}

Como se ha dicho ya, la propia noción de economía circular es ambigua y menos novedosa de lo que parece; ante la imposibilidad de tratar en estas páginas todo lo que indirectamente podría considerarse reconducible a ella, se atenderá únicamente a algunos de los instrumentos que la incorporan como nomen iuris. Y, precisamente también por razones vinculadas a la limitación de extensión, no podrá descenderse a todos los niveles de los instrumentos de aplicación, quedando por tanto para mejor ocasión el análisis de la multitud de estrategias y planes que en esta materia han sido puestos en marcha, tanto por las Comunidades Autónomas como por los entes locales.

\section{Aproximación preliminar: el contexto europeo}

A nivel de la UE, el primer instrumento impulsor de la economía circular se produce como se ha dicho ya en 2015, presentando un primer plan de acción en la materia. En aquel documento, se reconocía que la Comisión desarrollaría su análisis y propondría posibles medidas para superar los obstáculos innecesarios, "preservando al mismo tiempo el alto nivel de protección de la salud humana y del medio ambiente", pero no se daba mayor elaboración a los aspectos relacionados con esa salud humana ${ }^{75}$.

Ese plan de acción contemplaba los plásticos entre sus prioridades clave, y en su desarrollo se acabaría aprobando, en 2018, Una estrategia europea para el plástico en una economía circular ${ }^{76}$. En este texto aparecen referencias explícitas a los riesgos para la salud de la contaminación del entorno mediante plásticos. Se reconocía, por ejemplo, que la existencia de microplásticos en el aire, el agua

\footnotetext{
${ }^{75}$ COM (2015) 614 final, cit. El documento sólo contiene otra mención a la salud, en el marco de la expresión de la inquietud de la Comisión por el hecho de que cada vez más sustancias y productos químicos son fuente de preocupación para la salud humana o el medio ambiente y están sujetos a restricciones o prohibiciones, lo que debe ser tenido muy en cuenta para el desarrollo de los mercados de materias primas secundarias.

$76 \quad$ COM (2018) 28 final. <https://eur-lex.europa.eu/legalcontent/ES/TXT/DOC/?uri=CELEX:52018DC0028\&from=EN> [última consulta, 21 de agosto de 2021].
} 
potable y otros alimentos, como la sal o la miel, puede tener impactos todavía desconocidos sobre la salud humana. La economía circular del plástico se veía así como una oportunidad para encontrar soluciones innovadoras e impedir que los microplásticos lleguen al mar, debiendo investigarse para comprender mejor su origen, las rutas que siguen y sus efectos, entre otros ámbitos, también sobre la salud humana. La salud es igualmente un objetivo a conseguir en el marco de la identificación de posibles vías para que los productos químicos sean más fáciles de detectar en los flujos de reciclado, con el objetivo de facilitar el proceso o eliminar estas sustancias durante la operación. La Comisión reconoce en este documento de manera abierta que se necesita más investigación para mejorar nuestra comprensión de las fuentes y los impactos de los microplásticos, "incluidos sus efectos sobre el medio ambiente y la salud".

En el documento de cierre y balance de aquel primer plan de acción, la Comisión volvió a recalcar la importancia de la salud en relación primero con la contaminación por esos microplásticos ${ }^{77}$, y después más en general indicando que "la transición a la economía circular refuerza la cohesión social y territorial, favorece una distribución equilibrada del empleo, cumpliendo las normas de salud y seguridad, y permite generar un crecimiento equitativo y sostenible"78. Puede verse que la visión es altamente positiva, pero también retórica. Se aprecia en general un potencial propulsor de la economía circular hacia la protección de la salud, y se emplaza a investigaciones posteriores ante las incertidumbres existentes.

El segundo plan de acción de la UE en la materia se adoptó en marzo de 2020: se trata del Nuevo plan de acción para la economía circular por una Europa más limpia y más competitiva ${ }^{79}$. En este documento hay una mayor presencia, al

\footnotetext{
77 Se señala que los riesgos sanitarios y ambientales son los que justifican que se restrinja el uso de microplásticos añadidos deliberadamente y respaldan la recopilación de información sobre la medición y el etiquetado en el caso de los microplásticos liberados accidentalmente.

78 Informe de la Comisión al Parlamento Europeo, al Consejo, al Comité Económico y Social Europeo y al Comité de las Regiones sobre la aplicación del plan de acción para la economía circular, fechado el 4 de marzo de 2019. COM (2019) 190 final < https://eur-lex.europa.eu/legalcontent/ES/TXT/HTML/?uri=CELEX:52019DC0190\&from=EN > [última consulta, 21 de agosto de 2021].

79 COM (2020) 98 final <https://eur-lex.europa.eu/legalcontent/ES/TXT/HTML/?uri=CELEX:52020DC0098\&from=EN> [última consulta, 21 de agosto de 2021].
} 
menos nominal, de la salud; creo que en ello tiene mucho que ver el hecho de que este nuevo plan se inserta en una dinámica más amplia, la constituida por el llamado Pacto verde europeo ${ }^{80}$, y la hoja de ruta inicial de este pacto ya recoge desde sus aspiraciones basilares la protección de la salud y el bienestar de los ciudadanos frente a los riesgos y efectos medioambientales, al tiempo que entre sus políticas transformadoras incluye la "movilización de la industria en pro de una economía limpia y circular". Parece que se dan por sentados los vínculos entre la economía circular y la protección de la salud, aunque sin entrar en mayores detalles.

Por su parte, el nuevo plan de acción para la economía circular en la UE contempla los impactos sanitarios de esta de una manera un poco más completa. Así, se preocupa de expresar que la circularidad debe buscar reducir al mínimo la presencia de sustancias que susciten problemas para la salud o el medio ambiente en los materiales reciclados y los artículos que los contengan, y se presta especial atención a las exportaciones de residuos de la UE, que tal y como se vienen haciendo repercuten de forma negativa en el medio ambiente y la salud en los países de destino ${ }^{81}$.

Entre las principales medidas de desarrollo de este nuevo plan, se ha anunciado un nuevo Reglamento relativo a las pilas y baterías y sus residuos, que derogaría la Directiva 2006/66/CE y modificaría el Reglamento (UE) 2019/1020. El texto de la propuesta, hecho pública a finales del año pasado ${ }^{82}$, tiene en cuenta de forma genérica los impactos sanitarios en la determinación de la proporcionalidad de las medidas planteadas, y regula minuciosamente el almacenamiento, utilización y desecho seguro de las pilas y baterías. La materia es especialmente sensible porque estos productos requieren materiales que sólo se suministran desde un número reducido de países, y su extracción y refinado están asociados a importantes problemas sociales y ambientales; entre ellos, posibles peligros para

\footnotetext{
$80 \quad$ COM (2019) $640 \quad$ final $\quad$ https://eur-lex.europa.eu/legalcontent/ES/TXT/HTML/?uri=CELEX:52019DC0640\&from=ES> [última consulta, 21 de agosto de 2021].

${ }^{81}$ Al tiempo que, eso sí se recalca también, supone una pérdida de recursos y de oportunidades económicas para la industria del reciclado de la UE.

82 COM (2020) 798 final <https://eur-lex.europa.eu/legalcontent/EN/TXT/?uri=CELEX\%3A52020PC0798> [última consulta, 21 de agosto de 2021].
} 
la salud humana. De hecho, los "riesgos" se definen como la combinación de la probabilidad de que se produzcan daños y la gravedad de dichos daños, limitados a la salud humana, la seguridad de las personas, los bienes o el medio ambiente.

Es un avance prometedor, pero sigue haciéndose de manera aislada. Se pasa de formulaciones genéricas y grandilocuentes, a intentos de concretización sólo cuando se regula una materia determinada, donde los impactos en salud son evidentes, directos y negativos.

En febrero de 2021, la UE lanzó una Alianza Global para la Economía Circular y la Eficiencia en los Recursos (GACERE, por sus siglas en inglés ${ }^{83}$ ). Podría ser un buen actor para visibilizar las implicaciones de la economía circular en la protección de la salud, pero de momento y a la vista de su conformación no parece que vaya a ser así. La lista de organizaciones, organismos, redes y asociaciones que trabajan en materia de economía circular a nivel mundial es amplia, y en general no se cierran al reconocimiento de la salud como un factor importante en la transición circular, pero tampoco se ocupan con particular detalle de las cuestiones de salud ${ }^{84}$.

\section{La Estrategia Española de Economía Circular y el Plan de Acción 2021- 2023}

83 Más información puede verse en <https://ec.europa.eu/environment/international_issues/gacere.html> [última consulta, 21 de agosto de 2021].

84 Una revisión de los representantes de intereses más relevantes en esta materia, incluyendo también entidades allende la región europea, se puede ver en Hunt, Dale y George, Circular Economy...cit., p. 88-89. Como posibles socios que aportarían un mayor compromiso con el sesgo sanitario, los autores citan iniciativas como HEAL y el CHEM Trust, ambas inscritas en el registro de transparencia de grupos de interés de la UE. Una búsqueda rápida en ese registro devuelve 179 inscripciones a la búsqueda "circular economy", pero sólo una que aglutine también el término "health": se trata del Stichting Dutch Polymer Institute, inscrito además muy recientemente (17 de agosto de 2021). Las búsquedas con palabras clave en otros idiomas son aún más desoladoras. El registro puede consultarse en < https://ec.europa.eu/transparencyregister/public/homePage.do?redir=false\&locale=es> [última consulta, 21 de agosto de 2018]. Sobre el funcionamiento de estos grupos de interés puede verse el trabajo de Javier Ballina Díaz, "La formalización de las relaciones entre las instituciones europeas y los grupos de interés: encuentros y desencuentros", en María P. Andrés Sáenz de Santamaría (coord.), Una contribución a la europeización de la ciencia jurídica: Estudios sobre la Unión Europea, Thomson Reuters-Civitas. Cizur Menor, 2019, p. 675-700. 
El 2 de junio de 2020, el Consejo de Ministros aprobó el documento definitivo de la Estrategia Española de Economía Circular, en cuya elaboración había participado el Ministerio de Sanidad, identificando este departamento como una de las áreas estratégicas en que actuar para evolucionar hacia el nuevo modelo ${ }^{85}$. El mismo Ministerio forma también parte de la Comisión interministerial de economía circular86.

La protección de la salud figura como uno de los 13 principios que inspiran el documento (p. 26), y se asocia a la protección del medio ambiente en cuanto a las orientaciones estratégicas (p. 27). Se declina en clave laboral (p. 20), de consumo (p. 41-42), política industrial (p. 43) y agua (p. 44). Se incorpora a la vez como reto y oportunidad, y como riesgo y frontera de la circularidad.

Es un reto respecto a un mercado de trabajo que debe garantizar especialmente las condiciones de seguridad y salud en los puestos de trabajo afectados por el cambio a la economía circular. Es asimismo un riesgo del que debe informarse al consumidor, aunque siempre deberá garantizarse el menor impacto posible, funcionando entonces también como un límite. Es, en fin, una oportunidad, pues dado que el agua para consumo urbano ofrece hoy un alto grado de seguridad para la salud humana, puede pensarse en reducir con seguridad el uso de botellas de plástico.

Se trata de consideraciones superficiales y en todo caso parciales. El borrador sometido a información pública ${ }^{87}$, que era más detallado, contenía algunas previsiones puntuales concretas interesantes y más complejas, como el reconocimiento de que la velocidad de crecimiento de la economía verde supone una dificultad para determinar los efectos de los trabajos sobre la salud en todo

\footnotetext{
${ }^{85}$ Las otras áreas fueron turismo, agricultura y alimentación, transportes, movilidad y agenda urbana, consumo, asuntos sociales y laborales, seguridad, formación y hacienda.

86 Junto al Ministerio de Presidencia, Relaciones con las Cortes y Memoria Democrática, Ministerio de Política Territorial y Función Pública, Ministerio de Industria, Comercio y Turismo, Ministerio para la Transición Ecológica y Reto Democrático, Ministerio de Transporte, Movilidad y Agenda Urbana, Ministerio de Ciencia e Innovación, Ministerio de Hacienda, Ministerio de Consumo, Ministerio de Igualdad, Ministerio de Agricultura, Pesca y Alimentación, Ministerio de Trabajo y Economía Social, Ministerio de Asuntos Económicos y Transformación Digital, Ministerio de Interior, Ministerio de Derechos Sociales y Agenda 2030, Ministerio de Educación y Formación Profesional, y Ministerio de Universidades.

87 Un comentario crítico sobre aquel texto puede verse en Beltrán Puentes Cociña, “¿España Circular 2030? Comentario al borrador de la estrategia española de economía circular”, en Revista catalana de dret ambiental, 2018, vol. 9, núm. 2.
} 
su ciclo de vida, y que la aparición de empleos verdes concebidos para proteger el medio ambiente puede propiciar la exposición de los trabajadores a nuevos y/o mayores riesgos.

En ese sentido, se señalaba la necesidad de desarrollar nuevos estudios para conocer con detalle qué impactos, positivos o negativos, podría suponer la economía circular, de forma que se pueda estimar si repercute en un incremento en la seguridad y salud de los trabajadores 0 , por el contrario, se pueden estar originando riesgos que deriven en una mayor incidencia de determinados accidentes o enfermedades profesionales (p. 63). Se identificaba igualmente un efecto tractor de la utilización de la biomasa forestal como fuente de energía, por el no incremento de los niveles de emisión de contaminantes atmosféricos ( $p$. 92). También había alusiones expresas a la necesidad de mantener un mínimo de garantías sanitarias en relación con el uso de los lodos de depuración en el sector agrario (p. 107), la eliminación de basura marina (p. 116), los residuos fertilizantes (p. 126) y las aguas reutilizadas (p. 129). Por otro lado, se contemplaba también como una barrera, eventualmente incluso injustificada y por tanto que habría que revisar, las limitaciones técnicas actualmente existentes en la normativa aplicable sobre la reutilización de materias y productos en el sector de la construcción (p. 126)

Parte de esas consideraciones han sido volcadas en el I Plan de Acción de la AGE, aprobado el 25 de mayo de $2021^{88}$, que entre otras cosas reconoce a la economía circular un rol protagonista en el Plan de Recuperación, Transformación y Resiliencia, y en el Fondo Europeo de Desarrollo Regional.

Este Plan de Acción, que cubre el período 2021-2023, reconoce la protección del medio ambiente y de la salud humana como umbral de garantía del eje de actuación "materias primas secundarias" (p. 5 y 30-34) y de los nuevos marcos jurídicos que habrán de aprobarse para regular la producción y gestión de los residuos de construcción y demolición ${ }^{89}$, y la utilización de los lodos de depuración en el sector agrario (p. 23). La protección de la salud es también un

\footnotetext{
$88<$ https://www.miteco.gob.es/es/calidad-y-evaluacion-ambiental/temas/economiacircular/plan_accion_economia_circular_tcm30-529618.pdf> [última consulta, 22 de agosto de 2021].

${ }^{89}$ Se mencionan expresamente sustancias peligrosas como las fibras de asbestos.
} 
valor que habrá de inspirar el control y vigilancia de los residuos (p. 28), y un contenido de la estrategia de comunicación y difusión respecto a la circularidad de los plásticos (p. 39). Finalmente, también prevé que deberá estudiarse como riesgo emergente de los nuevos empleos y ocupaciones en desarrollo de la economía circular (p. 47).

A simple vista cabe apreciar que, al igual que ocurre con la UE, se ponen sobre la mesa algunos impactos, sobre todo directos y bastante elementales, de la economía circular en la salud. Resulta sorprendente, sin embargo, no encontrar ninguna referencia a materias que ya se han tratado en estas páginas, que caen dentro del ámbito competencial estatal, y donde esos impactos son cruzados, como el de la seguridad alimentaria y la nutrición ${ }^{90}$. También extraña que ni la Estrategia ni el Plan hagan referencia, siquiera sucinta, a los impactos indirectos en las enfermedades vinculadas a factores ambientales, como las respiratorias, los trastornos del desarrollo neurológico, cáncer o alteraciones endocrinas.

\section{Las leyes autonómicas sobre economía circular}

La única ley aprobada hasta el momento que se ocupa temáticamente de la economía circular (la Ley manchega 7/2019, de 29 de noviembre), arranca con una remisión genérica a la contribución de esta a la mejora del medio ambiente y con ello "de la vida y el bienestar de las personas" (art. 1)91. No aparecen empero, ni la salud ni la sanidad como sector específico, entre los ámbitos de

\footnotetext{
90 La relación entre seguridad y dieta alimentarias, resiliencia y huella de carbono queda puesta de manifiesto en el artículo 22 de la Ley 7/2021, de 20 de mayo, de cambio climático y transición energética, referido a la adquisición de alimentos por la AGE y sus organismos y entidades dependientes, y el establecimiento de condiciones especiales de ejecución que primen los alimentos frescos o de temporada, y con un ciclo corto de distribución. Sobre las deficiencias técnicas de este precepto puede verse las opiniones de Ximena Lazo Vitoria, " $i$ Habemus Ley de Cambio Climático!", en ObCP, 14 de junio de 2021. Disponible en <http://www.obcp.es/opiniones/habemus-ley-de-cambio-climatico> [última consulta, 25 de agosto de 2021].

${ }^{91}$ La previsión está en línea con una de las acotaciones finales de la exposición de motivos, la que señala que la norma pretende cumplir con los objetivos generales que establece el Estatuto de Autonomía, entre los cuales cabe poner de manifiesto el fomento de la calidad de vida, mediante la protección de la naturaleza y del medio ambiente y el desarrollo de los equipamientos sociales, con especial atención al medio rural. En la exposición de motivos también se indica que con la economía circular se espera una reducción del consumo de materias primas, así como de los impactos asociados a su producción unido a una reducción de la generación de residuos e impactos negativos derivados, mitigando las externalidades negativas para el medio ambiente, el clima, la diversidad biológica y la salud humana.
} 
aplicación de la economía circular, que son "agua, energía, industria, economía, comercio, consumo, educación, suelo y ordenación del territorio" (art. 2). La norma, que ha sido ampliamente criticada por la doctrina ${ }^{92}$, presenta así otra faceta reprochable. Teniendo en cuenta su marcado carácter programático, al menos sí se recoge el objetivo de "minimizar los riesgos para la salud humana y el medio ambiente por medio de una gestión eficiente y sostenible de los recursos" como uno de los que persigue la economía circular (art. 4.g).

La perspectiva es bien distinta en el texto borrador de Anteproyecto de Ley de economía circular que Andalucía sometió a información pública en diciembre de 202093. A falta de su tramitación parlamentaria, ese es un documento más ambicioso, también desde la perspectiva que nos ocupa. Entre otras cosas, la salud se configura como parte integrante del principio de cautela (art. 4) y se contemplan los centros de salud como gestores clave de la circularidad en los contratos referentes a servicios de hostelería, catering y restauración, así como en los contratos de suministros de carácter alimentario (art. 13). La puesta en peligro de la salud se tipifica como elemento determinante del carácter muy grave de las infracciones (art. 76), como factor que puede desencadenar la adopción de medidas provisionales antes de la iniciación del procedimiento sancionador (art. 79), y como criterio de graduación de las sanciones (art. 80). Estas son técnicas habituales de las leyes sectoriales ${ }^{94}$.

Y es que, en efecto, la consideración de la protección de la salud es mucho más explícita en la normativa autonómica sobre cambio climático, medioambiente y residuos, que son las otras perspectivas desde las que se ha regulado la economía circular, como ya se ha indicado con anterioridad. Entiendo que eso se debe a que en esas materias parece existir mayor consenso institucional y académico respecto a la influencia sanitaria, y mayor tradición de su estudio y consideración. De hecho, la legislación estatal en materia de cambio climático

\footnotetext{
92 Alenza García, "La economía circular..." cit., p. 231.

93 < https://www.juntadeandalucia.es/sites/default/files/2021-06/Borrador\%20LECA.pdf> [última consulta, 23 de agosto de 2021].

${ }^{94}$ De hecho, la Ley $8 / 2018$, de 8 de octubre, de medidas frente al cambio climático y para la transición hacia un nuevo modelo energético en Andalucía incluye esas técnicas instrumentales en materia sancionadora, y una prescripción material muy similar a la propuesta del borrador de norma circular que tiene que ver con el suministro de alimentos en los centros sanitarios, en su artículo 30.
} 
prevé específicamente el fomento de la mejora del conocimiento sobre los efectos del cambio climático en la salud pública y sobre las iniciativas encaminadas a su prevención. $Y$ dispone que, en el marco del Plan Nacional de Adaptación al Cambio Climático, se diseñarán e incluirán los objetivos estratégicos concretos, indicadores asociados y medidas de adaptación, encaminados a reducir o evitar los riesgos en la salud pública asociados al cambio climático, incluidos los riesgos emergentes (art. 23 de la Ley 7/2021, de 20 de mayo, de cambio climático y transición energética). En esa línea, la ley balear de cambio climático incluye el sector de la salud entre aquellos que requieren políticas sectoriales concretas (disposición adicional 6 $6^{\mathrm{a}}$ de la Ley 10/2019, de 22 de febrero, de cambio climático y transición energética), y la ley catalana contiene un artículo específico en materia de salud (art. 23 de la 16/2017, de 1 de agosto, del cambio climático). La ley andaluza, por su parte, incluye además la incidencia en la salud humana como uno de los factores a considerar necesariamente en el análisis y evaluación de riesgos por los instrumentos de planificación autonómica y local en materia de cambio climático (art. 20 de la Ley 8/2018, de 8 de octubre), constituyendo así la apuesta más decidida por la metodología de integración y evaluación de impactos sugerida por la OMS a la que más arriba se ha hecho también referencia, y en la línea de lo que viene disponiéndose en la normativa sectorial de residuos (por todas puede verse la regulación de la valoración de los riesgos en la reciente Ley 6/2021, de 17 de febrero, de residuos y suelos contaminados de Galicia).

En esa normativa existen previsiones específicas respecto a centros sanitarios y hospitalarios que engarzan con la economía circular, por ejemplo en Navarra, donde el artículo 24 de la Ley Foral 14/2018, de 18 de junio, de residuos y su fiscalidad, dispone que, con carácter general, en los edificios e instalaciones de las administraciones públicas no se pondrá a la venta agua en botellas de un solo uso, excepto precisamente en esos centros asistenciales. A mi juicio, la razón de ser de ese régimen especial95, que se prevé de manera afín en Baleares

\footnotetext{
95 La disposición ya figuraba de forma bastante similar en lo que aquí se está analizando en el texto del Proyecto de Ley inicial (publicado en el Boletín Oficial del Parlamento de Navarra núm. 157, de 22 de diciembre de 2017). Fue objeto de varias propuestas de enmienda (las núm. 9, 10 y 11, que pueden consultarse en el Boletín Oficial del mismo Parlamento núm. 25, de 27 de febrero de 2018). Las enmiendas tenían distintas sensibilidades y enfoque, pero en ningún caso
} 
(art. 25.3 de la Ley 8/2019, de 19 de febrero, de residuos y suelos contaminados de las Illes Balears $\left.{ }^{96}\right)$, tiene que ver con las peculiaridades del sector sanitario, aspecto al que se prestará atención para terminar este trabajo.

\section{ECONOMÍA CIRCULAR Y SANIDAD: POSIBILIDADES Y BARRERAS}

Existen diversos estudios recientes que alertan de la importante huella climática que genera la asistencia sanitaria ${ }^{97}$. El fenómeno es paradójico, porque esta actividad asistencial acaba así impactando negativamente en el bienestar de las propias comunidades a las que sirve. En este contexto, la sanidad debe plantearse cómo afrontar el reto ineludible de asegurar tanto la sostenibilidad del sistema sanitario98, como la del medio ambiente ${ }^{99}$. Para ello se ha subrayado el interés de aplicar en este sector la economía circular100, ante la gran cantidad de recursos que consume (agua, energía, metales y compuestos químicos, sobre todo) y el importante volumen de residuos que genera, por el empleo generalizado de productos de un solo uso, y por la acumulación de materiales, equipos y fármacos no utilizados, obsoletos o caducados. El porcentaje del PIB,

se cuestionó la excepción de los centros sanitarios y hospitalarios de la regla general de no poner a la venta botellas de agua de un solo uso.

96 También en este caso el Proyecto de Ley (Boletín Oficial del Parlamento de las Islas Baleares núm. 150, de 6 de julio de 2018) contenía desde un principio la excepción sanitaria ante la prohibición general de distribuir agua en envases de un solo uno en edificios e instalaciones de las administraciones públicas de las Islas. La medida planteó gran debate y distintas enmiendas y transacciones hasta la redacción finalmente aprobada del artículo, pero no llegó a cuestionarse nunca la razón del régimen especial de los centros sanitarios. Por cierto que, en esta Comunidad Autónoma, la misma excepción se predica también respecto a los centros educativos.

97 Puede verse el estudio y las referencias contenidas en Josh Karliner, Scott Slotterback, Richard Boyd, Ben Ashby y Kristian Steele, Huella climática del sector de la salud. Cómo contribuye el sector de la salud a la crisis climática global: oportunidades para la acción, Salud sin Daño-ARUP, 2019. Disponible en <https://saludsindanio.org/HuellaClimaticaSalud> [última consulta, 23 de agosto de 2021].

98 Desde distintas perspectivas y con el foco en el servicio público, pueden verse las recientes reflexiones de Miriam Cueto Pérez, "Buen gobierno y buena administración en la sanidad pública", en Revista vasca de administración pública, núm. 120, 2021, p. 61 y ss.

99 Chris Naylor et als., Towards environmentally sustainable health systems in Europe. A review of the evidence, OMS. Copenhagen, 2016.

100 La estructura económica constituye el más importante condicionante de la conformación de los sistemas de salud, ya sea directa o indirectamente, pues es el más poderoso determinante de la sociedad misma, y la enfermedad está profundamente influida por el modo de producción y consumo: María Dolores Vincent García, Concepción Alventosa Navarro, Eloísa Paniagua Caramanzana y A. Bermejo Martín, "Los determinantes de la conformación de los sistemas sanitarios", en Lamata (ed.), Manual de administración y gestión... cit., p. 38. 
el parque inmobiliario y la mano de obra que maneja el sector son también indicadores de tamaño que apuntan a que, como el resto de la industria, podría generarse ahorro y eficiencia aplicando la lógica circular. Los beneficios para la salud humana derivados de ese cambio tendrían que ver, de manera directa, con la reducción de costes de funcionamiento, que podrían reinvertirse en el propio servicio sanitario, y de forma indirecta, con la menor degradación del ambiente ${ }^{101}$. Las experiencias en el sector, por el momento, han cubierto desde modelos innovadores en contratación pública ${ }^{102}$, a planes para la reducción de desperdicios, alimentarios ${ }^{103}$ y de residuos ${ }^{104}$, pasando por la prescripción racional de medicamentos ${ }^{105}$, y el aumento de la tasa de reciclaje o del tiempo medio de vida útil de los dispositivos de diagnóstico y de intervención, que se pueden revalorizar y también compartirse en plataformas ${ }^{106}$. Son experiencias

\footnotetext{
101 Hunt, Dale y George, Circular Economy...cit., p. 35-37.

102 En general sobre este tema puede verse el trabajo de Javier García Amez, La contratación pública en el ámbito sanitario, Colex. A Coruña, 2020. Sobre la experiencia del servicio gallego de salud (SERGAS), es de interés la crónica de Luisa Abreu y Beatriz Piñeiro Lago, "¿Será viable mejorar los servicios de salud pública y disminuir su impacto en el medio ambiente, a través de la economía circular?", en Eco Circular, 30 de septiembre de 2020. Disponible en <https://ecocircular.com/> [última consulta, 23 de agosto de 2021].
}

103 En materia alimentaria también existen medidas para promover pautas saludables y sostenibles, e impulsar la incorporación de alimentos de proximidad, de temporada y de producción ecológica, en el ámbito de la restauración colectiva pública de las administraciones, incluyendo también los centros sanitarios. Así puede verse, en la Comunidad Valenciana, el Decreto $84 / 2018$, de 15 de junio, de fomento de una alimentación saludable y sostenible en centros de la Generalitat.

104 Junto a los residuos, otras áreas estratégicas del sector para la economía circular son los recursos hídricos, la energía, la edificación y el entorno, la alimentación y la movilidad y logística; puede verse que en su mayoría son cuestiones no asistenciales. Tienden a ser desarrolladas por empresas (mantenimiento, electromedicina, limpieza, restauración, transporte, lencería y lavandería, por ejemplo) que las asumen a partir de procesos de contratación pública. Sobre la experiencia de un conjunto de centros sanitarios andaluces: Alfonso Murcia Laguna y Gracia Buiza Camacho, "Economía circular en una red de seis hospitales públicos", en Técnica industrial, núm. 326, 2020, p. 46 y ss.

${ }^{105}$ La cuestión engarza con la circularidad del sector farmacéutico, aunque existen puntos en común, como el ajuste de las dosis, y la racionalidad del empaquetado, pues es habitual no sólo que haya sobrantes que desechar, sino también que el medicamento se componga, a veces injustificadamente, de envase externo, prospecto y blíster interno. Sobre estas cuestiones puede verse <https://www.sigre.es/> [última consulta, 24 de agosto de 2021]. La regulación contenida en el Real Decreto Legislativo 1/2015, de 24 de julio, por el que se aprueba el texto refundido de la Ley de garantías y uso racional de los medicamentos y productos sanitarios contiene referencias al impacto ambiental de los residuos de fármacos de uso humano y veterinario, pero no tanto respecto al embalaje.

106 Existen organizaciones que aglutinan iniciativas de este tipo. Por todas puede verse la Red Global de Hospitales Verdes y Saludables < https://www.hospitalesporlasaludambiental.net/> [última consulta, 23 de agosto de 2021]. 
que, a veces, se venían desarrollando de manera instintiva, sin relación expresa inicial con el concepto de economía circular107.

Los programas de eficiencia energética y el diseño de las construcciones son otros aspectos a trabajar, con planificación de zonas verdes y peatonales ${ }^{108}$, luz natural para espacios modulares y materiales sostenibles ${ }^{109}$. Confluyen en la materia aspectos clásicos, como la optimización de la provisión logística, con otros más novedosos. La digitalización y la telemedicina también se han subrayado así como de interés potencial desde esta perspectiva110.

No todas son, sin embargo, cuestiones socialmente pacíficas porque en un sector a la vanguardia de la tecnología, y donde los avances técnicos suponen ventajas privilegiadas, existe una cierta desconfianza hacia el empleo de equipamientos reacondicionados, por ejemplo ${ }^{111}$. Los plásticos de protección de elementos esterilizados parecen también algo irrenunciable para prevenir infecciones. La re-esterilización es un proceso costoso y emisivo, además. Y es que el sanitario es un sector cuyas connotaciones resultan críticas en términos también de seguridad, higiene, intimidad y confidencialidad; siempre habrá además en este ámbito más residuos que por su peligrosidad o régimen especial han de ser gestionados fuera del circuito circular, y límites normativos a la reutilización ${ }^{112}$. Además, el éxito pleno de la asistencia sanitaria es imposible, y

\footnotetext{
107 Murcia Laguna y Buiza Camacho, “Economía circular en..." cit., p. 50.

108 Dale, Hunt, Fischer, Hurley, Nowacki y George, Assessing the health... cit., p. 29.

109 En cuanto a medidas concretas de acción, y teniendo en cuenta también el sector privado, el Laboratorio de Ecoinnovación de la Obra Social de La Caixa y la Fundación Forum Ambiental da cuenta de una serie de iniciativas y casos prácticos de economía circular en materia de salud que van desde la prevención de la demanda sanitaria al ecodiseño de productos e instalaciones, pasando por el control de la cadena de suministro, la gestión circular de los productos médicos y los modelos de negocio: Guías de Economía Circular. Sector salud. Estratègies i solucions innovadores empresarials en l'àmbit de la salut. Disponible en < http://laboratorioecoinnovacion.com/publicaciones/guias-de-economia-circular> [última consulta, 23 de agosto de 2021].

110 Hunt, Dale y George, Circular Economy...cit., p. 36.

111 Geopolíticamente, los países en vías de desarrollo son muchas veces los destinatarios de ese material reacondicionado, lo que no está exento de polémica. Sobre las consideraciones de circularidad en los acuerdos comerciales puede verse el trabajo de Susana Borràs Pentinat, "Regulación del comercio internacional y economía circular: Los acuerdos de libre comercio y la transición hacia la economía circular en la Unión Europea" en Alba Nogueira y Xavier Vence (dir.), Redondear... cit., p. 327 y ss.

112 Mauricio Espaliat Canu, "La economía circular en el sector de la salud", en Hospitecnia, 27 de marzo de 2018. Disponible en < https://hospitecnia.com/documentacion/la-economia-circularsector-salud/> [última consulta, 23 de agosto de 2021].
} 
el resultado de ese "fracaso" difícilmente podrá considerarse un recurso circular ${ }^{113}$.

Sería necesario realizar una labor de educación y divulgación muy importante, para dar a conocer los beneficios de un cambio de modelo de consumo en hospitales y centros de salud ${ }^{114}$. La tecnología es un coadyuvante para la economía circular, pero la deshumanización de los servicios públicos, y en particular de la atención sanitaria, es un riesgo que se ve con recelo por la mayor parte de la ciudadanía, y que ha acabado estando más presente de lo que cabría haber esperado a raíz de la situación pandémica. No es además algo socialmente neutral pues, como ya se ha dicho, las personas y los grupos vulnerables son en esta materia también más sensibles. Lo son ya respecto a los procesos de digitalización en general ${ }^{115}$, pero es que además padecen también con más intensidad las desigualdades ligadas la economía circular y sus implicaciones sanitarias y ambientales. Por ello serían también, en su caso, potencialmente más beneficiados por los avances y sinergias que pudieran darse.

La crisis generada por la COVID-19 también puede verse como una oportunidad de la que salir reforzados a través de técnicas de economía circular. Se ha dicho así que la reducción del consumo lineal de recursos permite a los centros sanitarios ganar en resiliencia y contar con mayor autonomía respecto a proveedores externos, lo que hubiese resultado de mucha utilidad en los primeros tiempos de la pandemia ${ }^{116}$. El incremento de residuos vinculados a la

\footnotetext{
${ }^{113}$ Sobre este tema puede verse, respecto a la cremación y las responsabilidades funerarias públicas: Leopoldo Tolivar Alas, Los poderes públicos y el fuego, Tirant lo Blanch. Valencia, 2015, p. 173 y ss.

114 Hunt, Dale y George, Circular Economy...cit., p. 56.

115 Eva María Menéndez Sebastián y Javier Ballina Díaz, "Digital citizenship: fighting the digital divide", en European Review of Digital Administration \& Law, vol. 2, núm. 1, 2021. En el trabajo ya se han hecho referencias a las personas y grupos vulnerables por razones sociales, económicas y de género, además, es preciso también considerar la diversidad funcional, por la percepción de barreras estigmatizantes que pueden llevar a esa ciudadanía a la autoexclusión de los servicios digitales. Al respecto puede verse el trabajo de Florian Pethig, Julia Kroenung y Markus Noeltnerab, "A stigma power perspective on digital government service avoidance", en Government Information Quarterly, núm. 38, 2021. En la medida en que estas personas suelen además tener necesidades sanitarias acuciantes, la situación es doblemente preocupante.

116 Lars Thording, "The circular healthcare economy: suppliers, lawmakers-time's up", en MDDI Qmed, 27 de octubre de 2020. Disponible en < https://www.mddionline.com/general-
} 
crisis sanitaria, sobre todo los plásticos de un solo uso ${ }^{117}$, generó en su momento incluso la aprobación de normativa especial y no pocos retos de gestión ${ }^{118}$.

\section{CONCLUSIONES}

Los vínculos entre la economía circular y la protección de la salud, que resultan innegables en el contexto del cambio climático -con el que ambas realidades conectan-, no están suficientemente estudiados ni desde un punto de vista empírico ni tampoco desde las construcciones jurídicas. Dado el éxito de la fórmula de la economía circular, no parece factible que se orille a medio plazo, pese a que traslada un fenómeno que no es tan novedoso como a veces se sugiere.

Así las cosas, para conseguir un verdadero enfoque holístico, acabar con la regulación dispersa y las prácticas intuitivas y aisladas, y para evitar que los valores de la economía circular queden, en relación con la salud humana, en meras declaraciones de interés preciosistas pero inefectivas, es necesario profundizar en la identificación de impactos directos e indirectos, positivos y negativos, concomitancias, sinergias y compensaciones. Para ello es inaplazable, en primer lugar, perfilar mejor la noción jurídica de la economía circular, incierta como principio y ambigua como objetivo. También deberían investigarse y explicitarse las reglas de su maridaje con la protección de la salud en los instrumentos de la UE y en el marco de la Agenda 2030.

En relación con esto último, razonadas preconcepciones discursivas, después confirmadas por análisis conceptuales, apuntan a que ciertas metas y medios para conseguir el ODS 3, vinculado a la salud, se verían influenciados por el desempeño de prácticas de economía circular, directamente incardinables en cambio en el ODS 12, sobre producción y consumo responsable. Y ello a pesar de que, tal y como han avalado estudios empíricos especializados, en principio

hospital/circular-healthcare-economy-suppliers-lawmakerstimes > [última consulta, 23 de agosto de 2021].

117 Informe 4/2021 de la EEA: Impacts of COVID-19 on single-use plastic in Europe's environment. Disponible en < https://www.eea.europa.eu/publications/impacts-of-covid-19-on> [última consulta, 24 de agosto de 2021].

118 De la Varga Pastor, "La repercusión de la COVID-19... cit., p. 322 y ss. 
hay entre economía circular y ODS 3 un encaje muy débil. Los indicadores estadísticos de los ODS no ofrecen datos que sean fácilmente mesurables porque esa realidad es difícil de calibrar, pero también, sobre todo, porque el planteamiento de esos indicadores no se realizó desde esa lógica inspiradora de transversalidades tan complejas.

Por eso es fundamental integrar las cuestiones de salud en el diseño de las políticas y los instrumentos de economía circular, tanto programáticos como vinculantes. La implicación de expertos y las evaluaciones de impacto son esenciales. No faltan, en realidad, instrumentos metodológicos para evaluar el impacto de la economía circular en la protección de la salud, pero las técnicas no son unívocas ni directas, y se parte además de una llamativa indiferencia dogmática recíproca.

La revisión de los instrumentos vigentes permite concluir que los impactos de la economía circular para la salud humana se contemplan en general de dos formas, ambas insuficientes. Por un lado, de manera genérica, con remisiones vagas a efectos positivos comunes y a largo plazo; el efecto es, sobre todo, estético y retórico. Si se llega a concretizar es, por otro lado, sólo al descender a regulaciones particulares donde los impactos, también directos, pero aquí negativos, son más evidentes. Es lo que ocurre en la normativa planteada sobre microplásticos, pilas y baterías, por ejemplo.

Existen aspectos indirectos que precisan un boceto muy pulcro, con una adecuada evaluación e identificación de impactos, y de mejores perfiles conceptuales, a fin de aclarar naturaleza jurídica, límites, fronteras e influencias recíprocas. Desde la concreta perspectiva del sector de la asistencia sanitaria, identificado en general con la gestión hospitalaria y ambulatoria como actriz de la economía circular, se presentan además retos adicionales. Estos tienen que ver, entre otras cosas, con las peculiaridades de los productos y dotaciones de la sanidad, y con el crisol de actores, públicos y privados, asistenciales, logísticos y de servicios, que están involucrados.

El enfoque debe ser transversal, multidisciplinar y con perspectiva social. Se trata además de algo urgente; la crisis sanitaria no puede ser excusa para seguir dilatando esta tarea pues, como se ha indicado, la economía circular puede ser precisamente una oportunidad de resiliencia para el sector sanitario. 


\section{BIBLIOGRAFÍA}

Abreu, Luisa y Piñeiro Lago, Beatriz "¿Será viable mejorar los servicios de salud pública y disminuir su impacto en el medio ambiente, a través de la economía circular?", en Eco Circular, 30 de septiembre de 2020.

Alenza García, José Francisco, "La economía circular en el derecho ambiental", en Actualidad jurídica ambiental, núm. 102, 2020, p. 225-249.

Alenza García, José Francisco, "Principios clásicos para la nueva era del derecho ambiental", en Blanca Soro Mateo y Jesús Jordano Fraga (dir.), Viejos y nuevos principios del derecho ambiental, Tirant lo Blanch. Valencia, 2021, p. 11-39.

Armengol Rosinès, María Teresa, Salamero Teixidó, Laura y Plana Farran, Manel, "El desperdicio de alimentos como externalidad negativa: soluciones contenidas en la normativa francesa y propuestas para el caso español", Revista catalana de dret ambiental, vol. 11, núm 1, 2020.

Ballina Díaz, Javier, "La formalización de las relaciones entre las instituciones europeas y los grupos de interés: encuentros y desencuentros", en María P. Andrés Sáenz de Santamaría (coord.), Una contribución a la europeización de la ciencia jurídica: Estudios sobre la Unión Europea, Thomson Reuters-Civitas. Cizur Menor, 2019, p. 675-700.

Borràs Pentinat, Susana, "Regulación del comercio internacional y economía circular: Los acuerdos de libre comercio y la transición hacia la economía circular en la Unión Europea" en Redondear la economía circular. Del discurso oficial a las políticas necesarias, Thomson-Reuters Aranzadi. Cizur Menor, 2021, p. $327-$ 357.

Canals i Ametller, Dolors, "La efectividad de la regulación normativa del derecho a una vivienda digna y adecuada: una crítica desde el análisis social del derecho", en Natalia Paleo Mosquera (coord.), Políticas y derecho a la vivienda: gente sin casa y casas sin gente, Tirant lo Blanch. Valencia, 2020, p. 97-136.

Canals i Ametller, Dolors, "La operatividad de la economía circular y su gestión local", en José Esteve Pardo (dir.), La Agenda 2030: implicaciones y retos para 
las administraciones locales, Fundación Democracia y Gobierno Local. Madrid, 2021, p. 241-272.

Corvalán, Carlos F., Briggs, David J. y Zielhuis, Gerhard (ed.), Decision-making in environmental health: from evidence to action, OMS-E\&FN Spon. Londres, 2000.

Cueto Pérez, Miriam, "Buen gobierno y buena administración en la sanidad pública", en Revista vasca de administración pública, núm. 120, 2021, p. 61-102. Daher, Carolyn y Maquet, Oriol, "La movilidad sostenible como una oportunidad estratégica para la salud pública y el bienestar en los contextos urbanos", en Antonio Fortes Martín (dir.), Movilidad urbana sostenible y acción administrativa. Perspectiva social, estrategias jurídicas y políticas públicas de movilidad en el medio urbano, Thomson-Reuters Aranzadi. Cizur Menor, 2019, p. 419-461.

Dale, Nick, Hunt, Alistair, Fischer, Thomas B., Hurley, Fintan, Nowacki, Julia y George, Frank, Assessing the health impacts of a circular economy, OMS. Copenhagen, 2019.

Espaliat Canu, Mauricio, "La economía circular en el sector de la salud", en Hospitecnia, 27 de marzo de 2018.

Fortes Martín, Antonio, Los desplazamientos sostenibles en el derecho a la ciudad, lustel. Madrid, 2021.

García Amez, Javier, La contratación pública en el ámbito sanitario, Colex. A Coruña, 2020.

García, Ernest, Ecología e igualdad. Hacia una relectura de la teoría sociológica en un planeta que se ha quedado pequeño, Tirant lo Blanch. Valencia, 2021.

García Calvente, Yolanda, "Economía circular y ciudad", en María Rosario Alonso Ibáñez (dir.), La sostenibilidad socioeconómica de las ciudades. Estudios jurídicos, Tirant lo Blanch. Valencia, 2018, p. 315-339.

García Caracuel, María, "El papel de las smart cities en la transición hacia una economía circular y sus vías de financiación", en María Bertrán Girón y Julio Jiménez Escobar (dir.), El sistema jurídico ante la digitalización: estudios de derecho tributario, Tirant lo Blanch. Valencia, 2021, p. 235-271. 
Gaztelumendi, Iñaki, Tarí, Anna y Mora, David, Informe sobre Economía Circular aplicada al Turismo, SEGITTUR. Madrid, 2019.

Hunt, Alistair, Dale, Nick y George, Frank, Circular Economy and Health: opportunities and risks, OMS. Copenhagen, 2018.

Hussain, Sameera, Javadi, Dena, Andrey, Jean, Ghaffar, Abdul y Labonté, Ronald, "Health intersectoralism in the Sustainable Development Goal era: from theory to practice", en Globalization and Health, núm. 16, 2020.

Karliner, Josh, Slotterback, Scott, Boyd, Richard, Ashby, Ben y Steele, Kristian, Huella climática del sector de la salud. Cómo contribuye el sector de la salud a la crisis climática global: oportunidades para la acción, Salud sin Daño-ARUP, 2019.

Lazo Vitoria, Ximena (dir.), Compra pública verde, Atelier. Madrid, 2018.

Lazo Vitoria, Ximena, “iHabemus Ley de Cambio Climático!”, en ObCP, 14 de junio de 2021.

Llorente, Leandro y Vence, Xavier, “Decoupling or 'Decaffing'? The Underlying Conceptualization of Circular Economy in the European Union Monitoring Framework", en Sustainability 2019, 11(18), 4898.

Luisoni, Carlos A., "Prohibición de ingreso al territorio nacional de residuos peligrosos", en Revista de Derecho Ambiental, núm. 65, 2021, p. 149-156.

Menéndez Sebastián, Eva María y Ballina Díaz, Javier, "Digital citizenship: fighting the digital divide", en European Review of Digital Administration \& Law, vol. 2, núm. 1, 2021.

Murcia Laguna, Alfonso y Gracia Buiza Camacho, Gracia, "Economía circular en una red de seis hospitales públicos", en Técnica industrial, núm. 326, 2020, p. 46-52.

Naylor, Chris et als., Towards environmentally sustainable health systems in Europe. A review of the evidence, OMS. Copenhagen, 2016.

Nogueira López, Alba, "Cuadrar el círculo. El complejo equilibrio entre el impulso de la economía circular y unas reglas de mercado expansivas", en InDret. Revista para el análisis del derecho, núm. 3, 2019. 
Pardo Buendía, Mercedes, La evaluación del impacto ambiental y social para el siglo XXI: teorías, procesos, metodología, Fundamentos. Madrid, 2002.

Pérez de los Cobos Hernández, Elisa, "La contratación pública ecológica como instrumento de impulso de la economía circular", en Actualidad Jurídica Ambiental, núm. 102, 2020, p. 677-691.

Pérez Lagüela, Elena y Jiménez Herrero, Luis Miguel (coord.), Economía circular-espiral. Transición hacia un metabolismo económico cerrado, ASYPSEcobook. Madrid, 2019.

Pernás García, Juan José, "Compra pública circular: análisis de las barreras, posibilidades y límites del marco jurídico y organizativo actual y propuestas de mejora", en Alba Nogueira y Xavier Vence (dir.), Redondear la economía circular. Del discurso oficial a las políticas necesarias, Thomson-Reuters Aranzadi. Cizur Menor, 2021, p. 297-326.

Pethig, Florian, Kroenung, Julia y Noeltnerab, Markus, "A stigma power perspective on digital government service avoidance", en Government Information Quarterly, núm. 38, 2021.

Puentes Cociña, Beltrán, “¿España Circular 2030? Comentario al borrador de la estrategia española de economía circular", en Revista catalana de dret ambiental, 2018, vol. 9, núm. 2.

Rizos, Vasileios, Tuokko, Katia y Behrens, Arno, "The Circular Economy. A review of definitions, processes and impacts", en CEPS Research Report, núm. 8, 2017.

Rubio Cebrián, Santiago, "Economía sanitaria", en Fernando Lamata (ed.), Manual de administración y gestión sanitaria, Díaz de Santos. Madrid, 1998, p. 635-686.

Salamero Teixidó, Laura, "El desperdicio de alimentos", en Laura Salamero Teixidó (dir.), Manual básico de derecho alimentario, Tirant lo Blanch. Valencia, 2019, p. 109-140.

Salamero Teixidó, Laura, "Nuevo reto medioambiental en la Unión Europea: la prevención y gestión de los residuos alimentarios según la Directiva Marco de 
Residuos tras su última modificación", en Revista española de derecho administrativo, núm. 203, 2020, p. 249-280.

Santamaría Arinas, René Javier, "Economía circular: líneas maestras de un concepto jurídico en construcción", en Revista catalana de dret ambiental, vol. 10, núm. 1, 2019.

Santamaría Arinas, René Javier, “¿Hacia la economía circular europea sin los municipios?: una crítica sectorial de la Ley de racionalización y sostenibilidad de la administración local", en Revista vasca de administración pública, núm. 99100, 2014, p. 2671-2701.

Santamaría Arinas, René Javier, "Innovación normativa para la economía circular en leyes autonómicas", en Revista general de derecho administrativo, núm. 55, 2020.

Schroeder, Patrick, Anggraeni, Kartika y Weber, Uwe, "The Relevance of Circular Economy Practices to the Sustainable Development Goals", en Journal of Industrial Ecology, vol. 23, núm. 1, 2019, p. 77-95.

Thording, Lars, "The circular healthcare economy: suppliers, lawmakers-time's up", en MDDI Qmed, 27 de octubre de 2020.

Tojo, Naoko y Thidell, Äke, "Material recycling without hazardous substances. Interplay of two policy streams and impacts on industry", en Eléonore MaitreEkern, Carl Dalhammar y Hans Christian Bugge (ed.), Preventing environmental damage from products: an analysis of the policy and regulatory framework in Europe, Cambridge University Press. Cambridge, 2018, p. 253-275.

Tolivar Alas, Leopoldo, Los poderes públicos y el fuego, Tirant lo Blanch. Valencia, 2015.

Varga Pastor, Aitana de la, "La repercusión de la COVID-19 en la economía circular, en especial en la gestión de los residuos", en Jordi Jaria Manzano, Joseph Ramón Fuentes i Gaso, Paola Villavicencio Calzadilla y Víctor Merino Sancho (coord.), El impacto social de la COVID-19. Una visión desde el derecho, Tirant lo Blanch. Valencia, 2020, p. 306-347. 
Vaquera García, Antonio, De la tributación ambiental a las medidas financieras incentivadoras de la economía circular, Thomson-Reuters Aranzadi. Cizur Menor, 2020.

Vincent García, María Dolores, Alventosa Navarro, Concepción, Paniagua Caramanzana Eloísa y Bermejo Martín, A., "Los determinantes de la conformación de los sistemas sanitarios", en Fernando Lamata (ed.), Manual de administración y gestión sanitaria, Díaz de Santos. Madrid, 1998, p. 35-55.

Wright, Caradee Y., Godfrey, Linda, Armiento, Giovanna, Haywood, Lorren K., Inglesi-Lotz, Roula, Lyne, Katrina y Nayna Schwerdtle, Patricia, "Circular economy and environmental health in low- and middle-income countries", en Globalization and Health, núm. 15, 2019. 